\title{
The Architecture of Federations: Constitutions, Bargaining, and Moral Hazard *
}

\author{
Anke S. Kessler ${ }^{\dagger}$ \\ Simon Fraser University \\ Christoph Lülfesmann \\ Simon Fraser University \\ Gordon M. Myers \\ Simon Fraser University
}

\begin{abstract}
May 2008
Abstract

The paper studies a world where a region provides non-contractible essential inputs for the successful implementation of a local public policy project with spill-overs, and where bargaining between different levels of government may ensure efficient decision making ex post. We ask whether the authority over the public policy measure should rest with the local government or with the central government, allowing financial relationships within the federation to be designed optimally. Centralization is shown to dominate when governments are benevolent. With regionally biased governments, both centralization and decentralization are suboptimal as long as political bargaining does not take place. With bargaining, however, the first best can often be achieved under decentralization, but not under centralization. At the root of this result is the alignment of decision making over essential inputs and project size under decentralized governance.
\end{abstract}

JEL Classification: D23, D78, H21, H 77

\footnotetext{
*Preliminary versions were presented at the 2004 Queen's University Public Economics Workshop, the 2004 Meeting of German Economists Abroad, the 2005 DFG Conference on Institutional Design in Federal Systems, and at the 2006 CIAR Fall meeting. We thank Robin Boadway, Avner Greif, Kai Konrad, Ben Lockwood, Hao Li, Thorsten Persson, Michael Smart, David Wildasin, and seminar participants for helpful comments. We also thank SSHRC and CIFAR for their financial support. All errors are ours.

${ }^{\dagger}$ Corresponding Author. Simon Fraser University, CEPR and CIFAR. Address: Department of Economics, SFU, 8888 University Drive, Burnaby, BC, V5A 1S6. email: akessler@sfu.ca, phone: $+1-778-7823443$.
} 


\section{Introduction}

Adopting centralized or decentralized political decisionmaking is arguably the most critical design choice in federal systems. It is not surprising, therefore, that this issue has received considerable attention in the economic literature, starting with the pioneering work of Oates (1972). The main goal of the present paper is to study several empirically relevant - but previously disregarded - additions to the existing paradigm. In doing so, we are able to provide a novel argument why decentralization will often be beneficial. In line with previous work, our starting point is a scenario in which a policy project that involves spillovers across the federation can be pursued in one of its regions. A federal constitution assigns authority over project choice either to the regional jurisdiction, or to a central decisionmaker which may or may not be a benevolent government.

Models based on this standard setting usually posit that autonomous regional governments choose policies non-cooperatively. The failure to internalize spillovers on other regions then causes a suboptimal outcome under decentralization. Policy choice under centralization is hampered by other imperfections. Either the central authority is benevolent but subject to an exogenous requirement of policy uniformity. Or it is viewed as self-interested and composed of regionally biased federal politicians who, using agenda setting power, distort project choice away from the efficient level. Under this traditional approach, second best optimal governance then selects the regime that causes smaller distortions.

The present paper offers a different perspective of the tradeoffs at work. Our model uses the following building blocks. First, in a critical departure from most of the existing literature, we explicitly account for the possibility of negotiations between jurisdictions, and allow for an efficient outcome of the political bargaining process. ${ }^{1}$ Bargaining over political projects across different levels of government is often observed in reality, regardless of whether decision making power rests with the local or the central level of government. ${ }^{2}$ Furthermore, although transaction costs may

\footnotetext{
${ }^{1}$ To our knowledge, the only exception is Harstad (2006) which is discussed below.

${ }^{2} \mathrm{~A}$ good example of efficient inter-regional bargaining in a decentralized setting is Chernobyl. The remaining blocks of the Chernobyl nuclear power plant were finally shut down in December
} 
often prevent efficient bargaining, a frictionless world provides a benchmark against which alternative views of political negotiations can be judged. This is true a fortiori as there is a lack of compelling arguments why these frictions should be more severe in the decentralization regime than under centralization. In the end, it may not matter much whether regional delegates come together in a federal assembly to bargain for a 'centralized' political outcome, or whether they meet as representatives of decentralized regions to negotiate political issues of mutual concern.

Second, in order to successfully reach a mutually beneficial agreement in reality, horizontal or vertical transfers are often called for. This leads us to illuminate the role of grant systems in the determination of optimal governance, and to endogenize the constitutional provisions which are taken in that respect. While Oates' work emphasizes the role of Pigouvian grants and subsidies to resolve spillover problems, the more recent literature usually considers funding provisions as exogenously given, rather than being optimally set. In contrast, the present paper allows for cost and output grants, and investigates optimal grant design in both institutional regimes.

Finally, pursuing and implementing significant political projects often involve a time and resource consuming process. This process involves several stages, and a whole range of measures are paramount for ensuring the final success. Many of these efforts are subject to moral hazard considerations: they are intangible in nature and therefore, cannot be made part of cost sharing arrangements among the member states in a federation. We argue that one important goal of efficient governance is to design authority and funding systems in a way as to resolve or at least alleviate moral hazard concerns.

As an example that illustrates these issues, consider the ongoing Canada Line Rapid Transit Project, a rail-based rapid transit line linking the Vancouver Airport to downtown Vancouver, BC. With its $\$ 1.9$ billion (2006) capital cost, the transit line is one of the largest single public projects in the Vancouver area to date. On December

2000 after intense negotiations between Ukraine and the EU. Under the terms of the accord, the EU provided almost one billion US dollars in compensation, and agreed to help build two modern replacement nuclear reactors. Another example are national tax policies in the EU. Although the tax authority lies on the national (decentralized) level, member countries in 2006 agreed on exchanging information on capital flows in an attempt to crack down on tax evasion. 


\section{1, 2004 the local agency Greater Vancouver Transportation Authority (TransLink)} gave its final approval to the completion of this project. Notably, although Translink alone was put in charge of the Canada line, there had been prolonged negotiations involving agreements securing substantial funding contributions from both the federal and the provincial governments prior to the time of final approval. ${ }^{3}$ Moreover, even before approval, Translink had already spent an estimated sum of at least $\$ 30$ million on the project, primarily on the administration of the procurement process, property acquisition, community liaison, and public consultations.

The example exhibits the central features - mixed funding, political bargaining, and a costly planning process likely subject to moral hazard - that are often integral elements of public policy formation. All affected levels of government participate in the process through talks and negotiations. The final decision involves financial contributions through cost-sharing (matching) grants or other inter-governmental transfer mechanisms. ${ }^{4}$ The way in which this cost-sharing arises is partly codified in the federal constitution, and it is logically distinct from the question of who has authority to implement a certain project. Finally, the support of the local authority is essential for a successful implementation: there are local citizens to convince, local laws to modify, local red tape to overcome; and local infrastructure to make compatible with the project size and design.

The theoretical framework we develop to study the above features is simple. There

\footnotetext{
${ }^{3}$ To oversee procurement, design, construction, and implementation of the entire project from start to finish, TransLink created Canada Line Rapid Transit Inc. (CLCO, formerly RAVCO) as a special-purpose subsidiary. Apart from Translink itself, there are three other public funding sources: the federal government of Canada (\$421 million), the provincial government of British Columbia (\$ 387 million), and the Vancouver International Airport Authority (\$251 million). In 2006, the Provincial government agreed to pay additional $\$ 65$ million in exchange for design changes. Data Source: RAVCO Annual Report 2004 and Quarterly Report \# 1, January - March 2005.

${ }^{4}$ Since almost half of the population in British Columbia live in and around Vancouver, the benefits to the provincial government are obvious. The federal government's interest in the Canada Line can possibly be attributed to the fact that it is part of the city's preparations for hosting the 2010 Olympics. That the local authority would approve the project was not certain until the final vote in the Translink Board of Directors, a body composed of mayors and officials of all cities that are part of the Greater Vancouver Area. Indeed, there had been several rounds of voting, each of which was followed by a federal or provincial pledge for new funding. For a complete history of the project, see www.richmond.ca/discover/services/rav.htmhttp://www.richmond.ca/discover/services/rav.htm.
} 
is a federation consisting of two regions. In the 'project' region a local public project of variable size becomes available. If implemented, this policy project causes spillovers to a second 'composite' region that comprises a majority of the federation's inhabitants. Representatives from both regions initially sign a constitution that allocates authority rights, and specifies cost matching and output grant provisions. In a decentralized regime, the project region has the authority to determine the project size. In a centralized regime, authority rests with the federal government. Adopting a political economy view of government, the federal government does not pursue the overall public welfare, but is composed of regionally biased delegates who take decisions by majority rule. Hence, the composite region decides on project size. We account for the essential role of regional involvement by assuming that after signing the constitution, the project region can make preparatory investments into the project, which are non-contractible and thus subject to moral hazard. The return accrues in the form of reduced project cost or increased project quality, positively depends on implemented project size, and is identical across governance structures. Before the final decision on project size is made, regions may bargain over this decision to ensure a Pareto improving outcome, taking into account the regime-dependent default outcome. ${ }^{5}$

Analyzing this model, we first show that a centralized system works efficiently in a benchmark scenario where the central government is benevolent, and if an appropriate grant design is chosen ex ante. Specifically, while the central planner always implements the ex-post efficient policy level, efficient investments call for a combination of (non-Pigouvian) cost grants and output grants. In the remainder, we then adopt the more realistic view that central decisions are political rather than benevolent. For a scenario where political bargaining over final policies is infeasible, we show that an efficient outcome is impossible in a centralized and a decentralized regime. Since grants serve the dual role of implementing optimal investments and

\footnotetext{
${ }^{5}$ In the absence of moral hazard, political bargaining would always ensure an efficient outcome, regardless of the authority structure. But even without political bargaining, a constitutional Pigouvian grant easily resolves the externality problem, again rendering the choice of governance structure inconsequential. Hence, the choice between decentralization and centralization can be meaningfully addressed only if either subsidies are suboptimal and bargaining is inefficient, or if a moral hazard problem exists.
} 
optimal project decisions, an efficiency loss cannot be avoided: while an externalityinternalizing grant system can ensure efficient project decisions in either regime, the project region never captures the full benefit of its value-increasing investments. The latter are therefore too small in equilibrium. Overall, there is no clear cut ranking of central authority versus decentralized authority.

Finally, we analyze the full model by allowing for ex post political bargaining on the final project decision. With frictionless bargaining, the project choice is made efficiently in either governance structure, irrespective of the constitutional grant system. This outcome does not imply, however, that investments are also chosen optimally. Intuitively, investments affect the project region's payoff through two channels. As a direct effect, investments change its default payoff (the pre-negotiation payoff), as well as its share of the bargaining gain that is realized in equilibrium. In addition, there is an indirect or 'influence' effect, that arises because larger investments raise project quality (and reduce costs) and thus the default project size chosen by the region in charge. These two effects jointly determine the project region's investment incentives in both regimes, and their sign and size depends on the constitutional grant provision. One thus may think that efficient grant design can render the choice of authority structure meaningless. A central result of this paper, however, shows this conclusion to be invalid. Authority matters even with optimal grant design, and decentralization will generally dominate centralized governance.

To understand this finding, note that unlike the centralization regime, the direct and indirect effect under decentralization always work in the same direction. Large grants will induce the project region to implement a large project in default. Hence, both its default payoff and the direct investment effect are large in this case. At the same time, the influence effect is positive because a large default size boosts the negotiation surplus, part of which is reaped by the project region at the bargaining table. ${ }^{6}$ Since these two investment motives are aligned for the project region under decentralization, there is a grant system that achieves efficiency in this regime, generically so if spillovers are not too pronounced. Intuitively, large matching grants

\footnotetext{
${ }^{6}$ Since larger investments further raise the default project size which is (for substantial grants) already excessively large, the bargaining surplus (i.e., the gap between efficient total surplus, and the sum of default surpluses) goes up. Hence, the influence effect is positive.
} 
generate large project choices in the absence of an agreement, which unambiguously increases investment incentives. ${ }^{7}$

We show that a similar reasoning cannot be applied to the centralization regime. As a consequence, achieving optimal investments is generally impossible under centralized governance. To see this, remember that the direct effect on the project region's investments is large when the default project is large. But under centralization, the default policy is chosen by the majority region. Since this region naturally prefers a large project size only if it bears little of the associated costs, a large default policy now requires small constitutional grants. Small grants, however, render the influence effect as a crucial part of the project region's incentives negative: the project region wants to lobby the majority region to reduce the default project, and the only means to this end is lowering investments. ${ }^{8}$ Direct effect and influence effect thus work in opposite directions, a misalignment that prevents an efficient outcome under centralization. The institutional design matters and decentralization dominates because in contrast to centralization, it brings the investing region 'on side' for the success of the local project.

\section{Literature Review}

To which level of government should policy functions be assigned? This question has long not only been at the forefront of the political debate, but it has received significant scholarly attention. The classical theory of federalism (Musgrave, 1959; Oates, 1972) argues that regional governments cater better to the needs of their constituency than a central government because of the latter's tendency towards a uniform provision of public services across the federation. Conversely, the advantage of centralization lies in the internalization of all federation-wide spillover

\footnotetext{
${ }^{7}$ This finding also seems to confirm the intuition that with two instruments (cost and output grants) and two goals (implementing efficient cost reducing and value enhancing investments), an efficient outcome is feasible. As we will see below, however, this intuition fails for the centralization regime.

${ }^{8}$ Of course, large grants would make the influence effect positive. However, the majority region would then choose a small default project, which would diminish the direct effect and reduce investments.
} 
effects of local public decisions. The optimal allocation of government authority then balances these conflicting characteristics. While the traditional theory offers a conceptual framework and important guidelines for an understanding of hierarchical government, it rests on two strong assumptions: first, that the central government acts as a benevolent planner who pursues the common good and, second, that its policies must be uniform across all jurisdictions.

These problems are addressed in the more recent literature on federalism, which adopts a political-economy view of central government and questions uniformity of provision as a defining feature (and a disadvantage) of centralized public goods supply. ${ }^{9}$ In Besley and Coate (2003), the level of impure public goods under centralization is determined either by a minimum-willing coalition of regions, or by cooperative bargaining among the delegates from all regions. In the former scenario, public goods supply is inefficient for similar reasons as under decentralization: the ruling coalition ignores the well-being of minority districts. In the latter scenario, bargaining ensures that decisions are efficient, but the population from each region now has a strategic incentive to elect a representative with larger than median preferences for their local public good. As a consequence, centralization can be suboptimal even when polities are relatively homogeneous and the elected policy makers achieve a Pareto-optimal outcome ex post. In Lockwood (2002), regions can propose policy projects in a federal assembly. The projects to be realized are then selected in a sequential voting process. This paper finds that the equilibrium outcome depends on the degree (and the sign) of spill-overs which a regional project has on the majority of other regions. At the same time, however, the final allocation will be completely independent of the benefits to the home region in which it can be carried out. ${ }^{10}$

\footnotetext{
${ }^{9}$ See also the discussion in Oates (2005), who provides an excellent survey of the recent literature on federalism. For an early contribution which drops the assumption of a benevolent planner, see Ellingsen (1998). In his model, a pure public good is provided either in a decentralized fashion, or by a majority region that pursues its own interests under exogenous cost sharing rules.

${ }^{10}$ Several papers in the recent literature analyze federal systems with a hybrid organizational structure. The central government composed of individual regions directs public policies via majority vote. In addition, regions are allowed to top up these provisions (which can be interpreted as federal mandates) by individual choice. See Cremer and Palfrey (2000), Fernandez and Rogerson (2003), Alesina et al. (2005), and Hafer and Landa (2005). A general finding emerging from these papers is that a majority of regions prefers such a dual system over a pure centralized or a pure decentralized regime. See also Rubinchik-Pessach (2005) for a similar approach.
} 
In contrast to the existing literature, where cost-sharing rules are exogenous, we allow them to be designed optimally. ${ }^{11}$ This puts us in a position to address the basic question whether different institutional regimes continue to yield different economic outcomes when corrective grants and subsidies become choice parameters. Moreover, and more importantly, decentralization in these contributions is necessarily characterized by the total lack of cooperation with other regions in the federation, i.e., any political negotiations among regions in a decentralized system is ruled out. To our knowledge, the only other paper that explicitly studies political bargaining in decentralized settings is by Harstad (2006) and quite different in focus. The author considers a model where regions do not provide public inputs (investments) but have private information on their valuation of the project. The main result is that a mutual commitment to policy harmonization (uniform policies) may be advantageous in inter-regional negotiations because is reduces delay in bargaining.

By emphasizing the role of specific investments prior to the completion of the project, and in stressing the relevance of (re-)negotiations, our paper is also closely related to the literature on property rights and incomplete contracting (Grossman and Hart, 1986; Hart and Moore, 1990). There are two main differences. First, since we allow for monetary cost-sharing and output grants, the initial arrangement goes beyond a specification of institutional authority rights. By incorporating these elements which are prevalent in reality, we study contracting opportunities that are less incomplete than usually assumed in the literature. Second, the standard property-rights model posits that parties without property rights who in the absence of an agreement are excluded from the use of an asset realize a zero disagreement payoff. Conversely, in our federalism setting, externalities naturally arise even when negotiations are unsuccessful and when as a consequence, the region with authority rights chooses a project design that she finds privately optimal. This public-goods character of the joint project is also the focus of Besley and Ghatak (2001). The main finding of

\footnotetext{
${ }^{11}$ In most settings analyzed in the literature, moving from a decentralized to a centralized regime changes the financing rules of public projects. The usual assumption is that cost sharing is only feasible under centralization. This cost-pooling in the latter regime means that externalities are internalized at least to some degree, irrespective of whether project expenditures are chosen by a median voter, in a sequential political process, or by some appointed decision-maker. However, centralization does not completely solve the externality problem so that the eventual policy outcome will in general be inefficient.
} 
their paper is that in contrast to the main message from property-rights theory, the agent with the larger absolute benefit from the project should be assigned authority rights when the project realization causes externalities. ${ }^{12}$

The remainder of the paper proceeds as follows. Section 3 introduces the model, and Section 4 analyzes a benchmark scenario with benevolent central government. Section 5 compares the outcomes under centralization and decentralization when negotiations on project size is disregarded, while Section 6 incorporates political bargaining. Section 7 concludes.

\section{The Model}

We consider a federal system that is comprised of two jurisdictions, $j=A, B$. Region $A$ can pursue a public project $x$ of variable size which may cause an externality on the other, composite, region $B$. The model has three stages: at a constitutional prestage (stage 0 ), the regions select an authority structure (centralization, decentralization) with regard to the implementantion of the policy $x$, and in addition agree on a grant system that is detailed below. In a next stage (stage 1), region $A$ undertakes two types of public investments. The first investment (which we label $a$ ) increases the expected benefit of the policy measure $x$ that is pursued subsequently. For instance, if the project is a new airport that benefits both regions, its social value may be enhanced by investments in the surrounding infrastructure (streets, public transportation), in noise abatement, or in improving the planning procedure as an intangible asset. Secondly, the region may also undertake investments $e$ which

\footnotetext{
${ }^{12}$ While our basic setup is quite similar, framework and results of both papers differ significantly. Besley and Ghatak confine attention to a binary project choice, and in addition assume that both 'agents' privately benefit from the realization of the project regardless of investments. Accordingly, in their model the authority structure does not affect the default project size which in our setting, would make centralization and decentralization indistinguishable. Furthermore, in contrast to the present paper, the marginal investment effect on default payoffs depends on the authority structure; in particular, the respective marginal return is larger for the agent in control. The combination of this assumption with the feature of regime-independent default projects then yields the main result: the agent with higher stakes should have authority, no matter how important her relative investments are. Note also that in line with standard property-rights theory but in contrast to the present paper, Besley and Ghatak do not consider monetary (grant) schemes.
} 
decrease the expected costs of the policy project $x$ : it may spend effort in finding the most cost-efficient suppliers, or invest in research to find out the most costefficient design. After these investments are made, uncertainty on value and costs of the policy measure is resolved at the beginning of stage 2 . If the possibility of political bargaining among regions at this stage is left aside, the political institution with authority now chooses $x$ which is then implemented in stage 3 . Alternatively, regions $A$ and $B$ may be able to renegotiate the policy level by mutual consent. We label this latter scenario as 'federalism with politics', and will analyze it in Section 5 below.

Regions are governed by local governments, who by assumption act in the best interest of their respective constituencies. ${ }^{13}$ Also, we will impose two distinct behavioral assumptions on the central government. We first assume a benevolent planner who maximizes global welfare as is presumed in Oates' (1972) pioneering work. Subsequently, and more realistically, we then model the central government as a federal assembly that is composed of delegates from both jurisdictions, who pursue the interests of their home regions.

Let $x \in[0, \bar{x}]$ be the size or scope of the policy project, e.g., the quantity or quality of public goods provided, the capacity of an airport, or the rigidity of environmental standards. We denote the value-enhancing investments of region $A$ by $a \in R_{0}^{+}$. Likewise, cost-reducing investments are indicated as $e \in R_{0}^{+}$. The corresponding investment outlays are $\phi(a)$ and $\psi(e)$, respectively. In stage 2 , after investments have been made and uncertainty has been resolved, a project of size $x$ generates a total gross benefit measured in monetary terms by $V(x, a, \theta)$ across the federation. At the same time, it causes total implementation or opportunity costs $C(x, e, \theta)$. The variable $\theta$ is a random shock and distributed according to a continuous cumulative distribution function $F(\theta)$ on the support $[\underline{\theta}, \bar{\theta}]$. Benefits and costs of the 'status quo' policy $x=0$ are normalized to zero. Throughout the paper, we also impose

\footnotetext{
${ }^{13}$ This behavioral postulate serves to simplify the analysis. Of course, this assumption is very natural if individuals in a region have identical preferences. With heterogenous voters, regional representatives may be elected in an intraregional voting process. Voters will elect a politician who represents, e.g., the preferences of the regional median voter. Analyzing intraregional heterogenity would be straightforward in the present context and is therefore left out in our analysis.
} 
Assumption. All functions $V(\cdot), C(\cdot), \phi(\cdot)$ and $\psi(\cdot)$ are non-negative. Moreover, $V(\cdot), \phi(\cdot)$ and $\psi(\cdot)$ are increasing in their arguments, whereas $C(\cdot)$ is increasing in $x$ and $\theta$ and decreasing in $e$. For any $a, e, \theta$, all functions satisfy (subscripts denote derivatives)

a) $\lim _{x \rightarrow \bar{x}} V(x, a, \theta)-C(x, e, \theta)<0$ and $V(x, a, \theta)-C(x, e, \theta)>0$ for some $\theta<\bar{\theta}$ and some $x>0$. Also, $V_{x x} \leq 0, C_{x x}>0$.

b) $V_{a x}>0$ and $\lim _{x \rightarrow \bar{x}} V_{a}(x, a, \theta) \rightarrow \infty ; C_{x e}<0$ and $\lim _{x \rightarrow \bar{x}}-C_{e}(x, e, \theta) \rightarrow \infty$.

c) $V_{a a}(\cdot) \leq 0, \phi_{a a}(\cdot)>0, \phi(0)=\lim _{a \rightarrow 0} \phi_{a}(a)=0$ and $\lim _{a \rightarrow \infty} \phi_{a}(a)=\infty$.

d) $C_{e e} \geq 0, \psi_{e e}(\cdot)>0, \psi(0)=\lim _{e \rightarrow 0} \psi_{e}(e)=0$ and $\lim _{e \rightarrow \infty} \psi_{e}(e)=\infty$.

According to a), the socially efficient project size is unique, strictly positive in some states $\theta$ and always less than the maximal size $\bar{x}$, irrespective of investments. Part b) states that the return on cost-decreasing and value-enhancing investments increases in the project size. Specifically, the marginal return on investment increases without bounds. ${ }^{14}$ The convexity and Inada conditions in c) and d) ensure the optimality of some positive but finite investment levels.

For simplicity, we model the regional shares of total benefits from the project parametrically. Region $A$ reaps a gross return of $V^{A}=\beta V(\cdot)$ while the return of the composite region $B$ is $V^{B}=(1-\beta) V(\cdot)$. Thus, the parameter $\beta \in[0,1]$ measures the relative spillovers of the policy pursued in the project region $A$ on region $B .{ }^{15}$

We are especially concerned with the interplay between the governance structure and grant assignments both of which are chosen in what is called the constitutional prestage, stage $0 .{ }^{16}$ Throughout the paper, we suppose that grant payments can be

\footnotetext{
${ }^{14}$ This last assumption is dispensable but significantly eases the analysis in Section 5 below.

${ }^{15}$ For example, suppose $x$ is a pure public good and all individuals in the economy have identical valuations. Then, $V(\cdot)$ is the sum of individual utilities in the overall economy, and $\beta$ represents the fraction of individuals living in $A$ while $(1-\beta)$ indicates the fraction of individuals who live in $B$. The case where there are no externalities corresponds to $\beta=1$. The case of negative externalities, $(1-\beta)<0$ can (with appropriate adjustments) be analyzed analogously and is therefore disregarded in our formal analysis.

${ }^{16}$ Of course, the actual level of grant promises is not always fixed in a constitution, but on a case-by-case basis after a potential project has been identified. This alternative interpretation is fully compatible with our model.
} 
contingent on the project level $x$ and on its respective costs, $C(x, \cdot)$. On the other hand, the investments $(a, e)$ as well as the state $\theta$ and the project gross value $V(\cdot)$ are assumed to be non-contractible. Investments may be intangible assets which are hard to verify, or they may represent a bundle of measures so complex that it is impossible to really describe them contractually. Likewise, the gross value of the policy is a benefit which is idiosyncratic to either region, and thus cannot be observed by an enforcing party (such as a Federal Supreme Court).

In order to make our discussion as transparent as possible, we assume that regional preferences are described by quasi-linear utility functions. Monetary side payments thus enter additively, and utilities are fully transferable. Then, governance structure and grant system will at stage 0 be chosen so as to achieve a Pareto-optimal (i.e., welfare maximizing) outcome. In particular, distributional issues can be accounted for by initial lump-sum transfers across regions. ${ }^{17}$ We also allow regions to have access to the following grants which are prominent and wide spread in reality.

(i) Cost-matching grants. These grants are described by a parameter $\alpha$ that reflects the fraction of implementation costs $C(\cdot)$ to be borne by region $B$. If some $x$ is implemented, region $A$ thus receives a grant of size $\alpha C(x, \cdot)$ which is disbursed by the other region. ${ }^{18}$

(ii) Output grants. Region $A$ may be eligible for grant payments that are contingent on the project size $x$. Indicating $t$ as a payment per unit $x, A$ receives an output grant of size $t x$ when a policy $x$ is implemented.

In summary, we consider the following stage game which is played under perfect information.

Stage 0: Political representatives from each region decide on the governance struc-

\footnotetext{
${ }^{17}$ Clearly, the size and direction of these transfers depend on the governance structure in force prior to the stage 0 , and on the ex-ante bargaining strength of either region, respectively. We can be agnostic about these issues because they do not affect our analysis.

${ }^{18}$ Alternatively, grants may be paid by the central government and refinanced via general taxation that is imposed on either region. While the actual grant parameter may differ from $\alpha$ if region $A$ bears a part of the federal revenues, $\alpha$ in our model is then a measure for the effective payments flowing to region $A$ net of financing costs.
} 
ture and on a grant system, comprised of output and cost-matching grants. (In addition, there may be a non-contingent lump-sum payment made from one region to the other.)

Stage 1: Region $A$ can undertake cost-reducing investments $e$ and and value-enhancing investments $a$ into a policy measure, $x$.

Stage 2: Uncertainty is resolved. Representatives from $A$ and the composite region $B$ may negotiate the policy measure $x$ to be implemented, in exchange for side payments. Default payoffs depend on whether region $A$ (decentralization), or region $B$ (centralization) has authority over implementing the project.

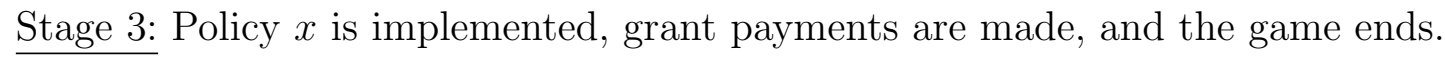

As a benchmark for future comparison, it is useful to compute the socially optimal policy level $x^{*}(\cdot)$ to be chosen at stage 3 . At that date, region $A$ has already expended $(a, e)$ and $\theta$ has been revealed. Accordingly, the efficient project size solves

$$
x^{*}(a, e, \theta)=\arg \max _{x \in[0, \bar{x}]} S(x, a, e, \theta) \equiv V(x, a, \theta)-C(x, e, \theta) .
$$

Under our previous assumptions, $x^{*}(a, e, \theta)>0$ for a nonempty set of realizations $\theta$, which is then uniquely determined by the first-order condition

$$
V_{x}\left(x^{*}, a, \theta\right)=C_{x}\left(x^{*}, e, \theta\right)
$$

Define $S^{*} \equiv S\left(x^{*}(a, e, \theta), a, e, \theta\right)$ as the maximum surplus in stage 3 and note that $S^{*}$ is independent of $\beta$ and strictly increasing in $(a, e)$ if $x^{*}(\cdot)>0$. In stage 1 , the socially optimal investment outlays $\left(a^{*}, e^{*}\right)$ to be undertaken by region A maximize the ex-ante expected overall surplus in the economy, i.e.,

$$
\left(a^{*}, e^{*}\right) \in \arg \max _{a, e \geq 0} E_{\theta}\left[S\left(x^{*}(\cdot), a, e, \theta\right)\right]-\phi(a)-\psi(e) .
$$

Again, our assumptions ensure that $\left(a^{*}, e^{*}\right)$ satisfies the corresponding first-order conditions which, using the envelope theorem, read

$$
E_{\theta} V_{a}\left(x^{*}(\cdot), e^{*}, \theta\right)=\phi_{a}\left(a^{*}\right) \quad \text { and } \quad-E_{\theta} C_{e}\left(x^{*}(\cdot), e^{*}, \theta\right)=\psi_{e}\left(e^{*}\right)
$$


As we would expect, the marginal expected returns from investments (evaluated at the conditionally optimal policy level) should be equal to marginal investments costs at the optimum.

In what follows, we indicate the first-best project size in a state $\theta$ as $x^{F B}(\cdot)=$ $x^{*}\left(a^{*}, e^{*}, \theta\right)$. Also, let $a^{*}(e)$ (and $e^{*}(a)$, respectively) be the conditionally optimal level of $a$ for any given $e$ (and the conditionally optimal level of $e$ for any given $a$, respectively). We are now prepared for an equilibrium analysis under different assumptions on government behavior.

\section{Benevolent Central Planner}

To start with, consider a centralized governance structure in which a benevolent government $P$ has authority over the policy measure $x$. Denoting as $S^{j}(\cdot)$ the gross surplus of region $j$ and recalling that distributional issues are irrelevant in our setting, this planner chooses $x$ in stage 3 so as to maximize

$$
S(\cdot)=S^{A}(\cdot)+S^{B}(\cdot)=V(x, a, \theta)-C(x, e, \theta) .
$$

Clearly, the resulting policy level $x^{*}(e, a, \theta)$ is efficient for any $(a, e)$ and in any state of the world $\theta$. We can now investigate the investment decisions of region $A$ in stage 1. For any constitutional grant assignment $(t, \alpha)$, the region chooses $a$ and $e$ to maximize the net surplus of its inhabitants ( $P$ stands for Benevolent Planner),

$$
U_{P}^{A}(\cdot)=E_{\theta}\left\{\beta V\left(x^{*}, a, \theta\right)+t x^{*}-(1-\alpha) C\left(x^{*}, e, \theta\right)\right\}-\phi(a)-\psi(e) .
$$

Maximization of this program yields the following first-order conditions for the region's equilibrium investments:

$$
\begin{aligned}
E_{\theta}\left\{\beta V_{a}\left(x^{*}, a, \theta\right)+\left[\beta V_{x}\left(x^{*}, \cdot\right)+t-(1-\alpha) C_{x}\left(x^{*}\right)\right] \frac{d x^{*}}{d a}\right\} & =\phi_{a}(a), \\
E_{\theta}\left\{-(1-\alpha) C_{e}\left(x^{*}, e, \theta\right)+\left[\beta V_{x}\left(x^{*}, \cdot\right)+t-(1-\alpha) C_{x}\left(x^{*}\right)\right] \frac{d x^{*}}{d e}\right\} & =\psi_{e}(e) .
\end{aligned}
$$

The first terms in (6) and in (7), respectively, represent the (positive) marginal direct effect of investments on $A$ 's payoff. The second term in both conditions indicates an 
indirect effect which arises because region $A$ has preferences over but cannot directly choose the project size: since the central government's selection of $x^{*}(a, e, \theta)$ depends on region $A$ 's effort, the region indirectly affects the central policy. Notice that the indirect effect is positive if and only if $x^{A}(\cdot)>x^{*}(\cdot)$, and vice versa: If region $A$ is eligible for large grant payments, it is interested in a larger policy than $P$ will provide, and higher investments are a tool to achieve this goal.

To further assess conditions (6) and (7), suppose first $\alpha=t=0$, a situation where $A$ receives no monetary support from the other regions in the federation. Then, the indirect effect in either condition is negative whenever $\beta<1$ because $x^{*}(\cdot)$ is increasing in $a$ and $e$, and $V_{x}\left(x^{*}, \cdot\right)-C_{x}\left(x^{*}(\cdot)=0\right.$ by the definition of $x^{*}(\cdot)$. In absence of grant payments, the region aims to reduce the policy level $x$ through reduced investments because it bears the entire costs while receiving only a fraction $\beta$ of the accompanied social benefits. In addition, the direct effect in (6) is smaller than the social marginal return from value-increasing investments for any $\beta<1$. For these reasons, the region unambiguously underinvests not only in benefit enhancement, despite being full residual claimant for its cost savings, also in cost reduction when $\alpha=t=0$.

We can now ask whether cost or quantity grants can remedy this underinvestment problem. The answer is positive, by the following arguments. Note that the indirect effect increases in $t$ without bounds because $x^{*}(\cdot)$ remains unaffected. Hence, for any arbitrary $\alpha$, some $t^{*}(\alpha)$ renders the indirect effect strictly positive and satisfies (6) for $a=a^{*}(e)$. Next, consider (7) for $t=t^{*}(\alpha)$. Again, the indirect effect is positive which implies that $A$ overinvests in cost-reducing activities for $\alpha=0$. At the same time, increasing $\alpha$ while fixing $t=t^{*}(\alpha)$ reduces $e$ arbitrarily. ${ }^{19}$ As a result, there must exist some combination $\left(\alpha^{*}, t^{*}\left(\alpha^{*}\right)\right)$ which implements the fixed points $a=a^{*}(e)$ and $e=e^{*}(a)$, and we have

Proposition 1. Consider centralization with a benevolent government. Then, some constitutional policy $\left(\alpha^{*}>0, t^{*}>0\right)$ implements a first-best outcome. Moreover, under the optimal grant design, region A would prefer a policy size larger than the

\footnotetext{
${ }^{19} \mathrm{We}$ cannot rule out some $\alpha>1$ to be optimal here, in order to prevent an overshooting of $A$ 's cost-reducing investments.
} 
one chosen in equilibrium.

Centralization is an efficient governance structure if grant design is optimal and if the central government maximizes social welfare. We also obtain that in general, both cost and output grants are necessary to sustain a first-best outcome. ${ }^{20}$ These findings have intuitive appeal. With a benevolent central government, grants serve no role in achieving an ex-post efficient policy outcome: given the preferences of the federal decisionmaker, $x^{*}$ prevails regardless of constitutional grant provisions. Rather, the purpose of grants is to fine tune the project region's incentives to invest in cost reduction and benefit enhancement, which quite naturally requires a properly designed combination of output and cost grants.

The Proposition also conveys a somewhat counterintuitive result, namely that optimal grants are so substantial that region $A$ prefers a larger project than the one actually implemented by the central government. To see why, consider 'small' grants for which region $A$ would prefer a project size less or equal to $x^{*}(\cdot)$. Inspecting (6) and noting that the indirect effect is non-positive, shows that with positive externalities $\beta>0$, the region will still underinvest in value increasing measures as it reaps only a fraction of the associated benefits. Remedying this non-internalization problem requires larger grants: the region $A$ would then prefer a project size in excess of $x^{*}(\cdot)$, which renders the indirect effect positive. In simple terms, large grants boost the project region's investment incentives because a larger project size implies larger absolute grant payments.

Before closing this Section, notice that the opportunity to bargain over the ex-post chosen policy level would not affect the benevolent-planner scenario: since $P$ implements the Pareto efficient project level $x^{*}(\cdot)$, there is no room for further bargaining in equilibrium. We should thus note that the efficiency properties of centralization with a benevolent government apply whether or not political bargaining is feasible. From now on, the present paper will drop the assumption of a benevolent central government. The next Section introduces a more realistic representation of deci-

\footnotetext{
${ }^{20}$ If the region invests only in value enhancement, the instruments $\alpha$ and $t$ substitute each other, and using only one of them is sufficient for implementing a efficient outcome. Conversely, with only cost reducing investments, an output grant $t$ always achieves efficiency whereas in general, a cost grant $\alpha$ does not: it causes direct and indirect effect move in opposite directions.
} 
sionmaking under centralized authority, which we will then use for comparing the outcomes under centralization and decentralization, first in a setting where political ex-post bargaining is assumed to be infeasible.

\section{$5 \quad$ Federalism without Political Bargaining}

The present Section addresses the investment and policy choices in a federal system where regions do not negotiate with each other to determine the final policy outcome, but in which the central outcome is chosen in a political process. In its decentralization variant, this setting can be seen as a reassessment of the arguments in Oates (1972) for a scenario where regions can undertake non-contractible investments prior to the implementation of policy projects. Specifically, while Oates showed that corrective grants implement an efficient outcome under decentralization, we can ask whether or not they have the same effect in the present setting. Subsection 5.1 considers decentralization where region $A$ has authority to choose and implement its preferred policy. Subsection 5.2 explores centralized decisionmaking in a stylized democratic process with majority rule. In either case, we analyze the implications of an efficient grant design at the constitutional prestage. In addition, we take a closer look at the outcome which prevails in absence of grant promises made to region $A$.

\subsection{Decentralization}

If the authority to decide on $x$ lies with the project region $A$, the regional government chooses the project size to maximize regional welfare. ${ }^{21}$

Suppose a grant system $(\alpha, t)$ was agreed upon and put in place at stage 0 . Then,

\footnotetext{
${ }^{21}$ While we disregard intra-regional heterogeneity for simplicity, we could easily incorporate it by assuming regional decisions to be taken by majority voting under some given financing rule. Then, the median voter theorem applies and regional policies are determined by the preferences of the individual with median preferences (see, e.g., Besley and Coate, 2003; Alesina et al., 2001). Besley and Coate (1997) show that this result extends to mutidimensional policy spaces in two candidate elections, which can arise endogenously in their model. As is well-known, such democratic processes will not maximize regional welfare in an utilitarian sense if median preferences differ from mean preferences.
} 
region $A$ will in stage 3 implement a policy $x^{A}$ which maximizes its continuation utility

$$
S^{A}(x, a, e, \theta, \alpha, t)=\beta V(x, a, \theta)+t x-(1-\alpha) C(x, e, \theta)
$$

in each state $\theta$. The corresponding first-order condition for an interior solution $x^{A}>0$ reads

$$
\beta V_{x}\left(x^{A}, a, \theta\right)+t=(1-\alpha) C_{x}(x, e, \theta) .
$$

One can easily check that $x^{A}(\cdot)$ is strictly increasing in $(a, e)$ and in $t$, and strictly decreasing in $\alpha$. For the Pigouvian cost subsidy $\alpha=1-\beta$ and $t=0$, region $A$ implements the ex-post efficient policy $x^{*}(\cdot)$. Conversely, without any grant assignment, $\alpha=t=0, x^{A}(\cdot)<x^{*}(\cdot)$ whenever spillovers are present, $\beta<1$. Anticipating its subsequent implementation decision, region $A$ chooses it investments at stage 1 so as to maximize (D stands for Decentralization)

$$
U_{D}^{A}(\cdot)=E_{\theta}\left\{\beta V\left(x^{A}, a, \theta\right)+t x^{A}-(1-\alpha) C\left(x^{A}, e, \theta\right)\right\}-\phi(a)-\psi(e) .
$$

Under our technical assumptions and using the envelope theorem, the equilibrium investments $\left(a^{D}, e^{D}\right)$ are then implicitly determined by the first-order conditions

$$
E_{\theta} \beta V_{a}\left(x^{A}, a, \theta\right)=\phi_{a}(a)
$$

and

$$
-E_{\theta}(1-\alpha) C_{e}\left(x^{A}, e, \theta\right)=\psi_{e}(e)
$$

If region $A$ receives no grants, it will choose a level of cost-reducing investments which is optimal for the (suboptimally small) policy $x^{A}$ that is subsequently implemented. Conversely, value-increasing investments will be too small even if set in relation to $x^{A}$, because region $A$ disregards the effect of its investment on the other region for $\beta<1$. Only for $\beta=1$ where spillovers are absent, both types of investments are chosen efficiently and $x^{A}(\cdot)=x^{*}(\cdot)$, with the consequence of a first-best outcome.

Consider now cost and output subsidies. The most prominent examples of such grant systems are corrective 'Pigouvian' grants that help regional decisionmakers to internalize external effects, and induce them to implement an efficient outcome, here, $x^{*}(\cdot)$. The present setting features a continuum of Pigouvian grant 
systems, specifically, the pure cost grant $\alpha^{P}=1-\beta$ and the pure output grant $t^{P}=E_{\theta}(1-\beta) V_{x}\left(x^{*}, \cdot\right) / x^{*}(\cdot)$. But more generally, each combination $(\alpha, t)^{P}$ satisfying $t(\alpha)=(1-\alpha) C_{x}\left(x^{*}(\cdot), \cdot\right)-\beta V_{x}\left(x^{*}(\cdot)\right)$ at equilibrium investment levels for given grant parameters, implements the ex-post efficient project size $x^{A}(\cdot)=x^{B}(\cdot)=x^{*}(\cdot)$. Throughout the paper, we will show that in our framework, Pigouvian subsidies are optimal only in special circumstances, and that cost and output grants are not mere substitutes to each other. Output subsidies are often preferable over cost subsidies, while a combination of both forms of grants is sometimes strictly dominant.

In the current context of decentralization, we now show that even with optimal grant design, an ex-post efficient policy choice $x^{*}(\cdot)$ is necessarily incompatible with the goal of achieving efficient value-enhancing investments $a^{*}(e)$ : the first-order condition (11) immediately reveals that for any - even arbitrary - policy $x^{A}$ which is implemented, investment incentives are always smaller than the conditionally efficient level (given $x^{A}$ ) for any $\beta<1$. This negative finding, though, does not extend to cost-reducing investments. Here, $\alpha=0$ and an output grant that implements $x^{A}=x^{*}(\cdot)$ guarantees efficient cost reduction $e^{*}(a)$, as is easily seen from (12). Note also that under the second-best grant design, the regions will rationally never use a cost subsidy $\alpha>0$. Any cost-matching grant distorts $A$ 's incentives to invest in cost reduction, simply because the region no longer bears the full project costs. On the other hand, a positive output grant is desirable, inducing region $A$ to choose a larger project size and to internalize the project externality to some degree. These arguments yield

Proposition 2. Consider decentralization without ex-post bargaining. Then, an optimal federal constitution will comprise output grants $t^{*}>0$ but no cost-matching grants, $\alpha^{*}=0$. Moreover,

(1) An efficient outcome prevails if the region can undertake only cost-reducing investments. In this case, the optimal subsidy is a Pigouvian output grant.

(2) With spillovers $(\beta<1)$, an efficient outcome is infeasible if the region can undertake value-increasing investments, or both investments. Under the optimal grant, the region implements a policy $x^{A}(\cdot) \geq x^{*}(\cdot)$, it underinvests in value enhancement, and it invests optimally (given $x^{A}$ ) into cost reduction. 
Proof: see the Appendix.

The outcome under decentralization is necessarily inefficient whenever there is any role for value-increasing investments. The reason for this deficiency should be clear. While cost and output grants can control for the project size that is selected by region $A$, they cannot tackle the externality which arises because $A$ does not appropriate the full social return of its value-increasing activities, no matter what the policy level. This causes a trade-off between larger investments if $x^{A}(\cdot)$ is raised above $x^{*}(\cdot)$, and the reduction in allocative efficiency which comes along with it. We already mentioned that this tradeoff does not arise for cost-reducing investments as long as the constitution does not prescribe any cost subsidy, $\alpha=0$. As an immediate consequence, the equilibrium policy with optimal grants under decentralization is never smaller but possibly larger than efficient. While counterintuitive at first glance, an excessive project size emerges because a bigger project boosts valueincreasing effort while - at the margin - leaving the equilibrium level of cost-reducing investments unaffected. Aggregate grant payments in the decentralization regime should thus exceed those of a Pigouvian subsidy in order to ensure a second-best outcome.

Interestingly, our findings show that an efficient outcome with only cost-reducing investments requires the regions not to use cost matching grants in their constitution. The explanation is simple. Any cost grant counterbalances the region's incentive to invest in cost reducing measures for any given project size, because it now shares the marginal benefits of its actions with the other region. Accordingly, despite its preponderance in reality, cost matching grants are no useful instruments in an economic scenario with moral hazard element, and in which there is no ex post interregional bargaining on project size. ${ }^{22}$

Our results so far show that with a benevolent central government, centralized authority on project implementation strictly dominates decentralization, even if cor-

\footnotetext{
${ }^{22}$ The same logic immediately applies to the case of centralization. In contrast, Section 6 below shows that the argument becomes invalid in a setting where regions can negotiate the project size.
} 
rective grants can be optimally chosen. Another interesting issue worth addressing is whether the unambiguous ranking of benevolent centralization in the tradition of Oates, and decentralization with a regional planner continues to hold for nonoptimal subsidy levels. Some answers are given in

Proposition 3. Without a grant policy, $t=\alpha=0$, decentralization may dominate centralized governance with a benevolent planner. Also, for any arbitrary combination of (Pigouvian) grants $(\alpha, t)$ that yield $x^{A}=x^{*}$, both regimes yield identical outcomes where region $A$ underinvests in cost reduction (unless $\alpha=0$ ), as well as in value-enhancing effort.

Proof: See the Appendix which presents an example where decentralization dominates for any degree of spillovers, $\beta<1$, given $(\alpha, t)=(0,0)$. The second statement immediately follows from inspection of the respective first-order conditions.

When grants are not optimally set, centralization is not necessarily more efficient, even though we allow for a benevolent central planner and do not impose policy uniformity across regions. As Proposition 3 shows, decentralization may dominate, notwithstanding the fact that regional government takes neither the external effects of its investment choice nor those of its policy selection into account. Intuitively, with small or no grants, the project region has an interest to lower the project level that is chosen by the benevolent planner under centralization. This can be achieved by reducing investments, a motive which is absent in the decentralization regime where region $A$ is in control of the final policy choice. Investment efficiency will thus be higher under decentralization, and decentralization can be preferable overall even though the chosen project size is inefficiently small. The Proposition also says that interestingly, Pigouvian grants induce identical outcomes across regimes. Since these grants align the desired output choice of central and regional government, they also trigger identical investment responses.

Returning to optimal grants, the perhaps most striking difference between our and the traditional analysis, though, is that even the optimal grant system does not resolve the underinvestment problem under decentralization. This is because in contrast to centralization with benevolent government where grants leave the final 
policy choice unaffected, grants under decentralization serve the dual purpose of fine tuning investments, and affecting the project size. We find that output or cost contingent transfers cannot be set up in a way that efficient investments and an efficient allocative outcome prevail at the same time. The next subsection shows that a similar inefficiency exists under centralization when the central government is political rather than benevolent.

\subsection{Centralization}

In reality, central governments rarely act as benevolent entities. We now suppose that the central government is a federal assembly, composed of representatives from both regions. These delegates pursue their own idiosyncratic interests which, as said before, coincide across all individuals within each region for simplicity. This setup encompasses parliamentary systems in which political decisions are taken by some form of majority vote in a federal assembly (e.g., as in the UK, Germany or Canada), as well as a Presidential systems in which some elected decisionmaker is assigned for making these decisions (as, e.g., in the US or in France).

Decisions are taken via majority rule so that the region with more delegates in the assembly can enforce its preferred policy. If region $A$ is the majority region, the outcome clearly coincides with the one under decentralization. To make the subsequent analysis meaningful, let us thus suppose that delegates from the composite region $B$ form the majority. ${ }^{23}$ If region $B$ has authority in the democratic process, it will in stage 3 choose a policy $x^{B}$ to maximize

$$
S^{B}(a, e, \theta, \alpha, t)=(1-\beta) V(x, a, \theta)-t x-\alpha C(x, e, \theta),
$$

and the corresponding first-order condition for interior solutions reads

$$
(1-\beta) V_{x}\left(x^{B}, a, \theta\right)-t=\alpha C_{x}\left(x^{B}, e, \theta\right) .
$$

In contrast to the decentralization regime, $x^{B}(\cdot)$ now strictly decreases in $t$ and $\alpha$ because region $B$ dislikes grant payments. As under decentralization, for $\alpha=1-\beta$

\footnotetext{
${ }^{23}$ Alternatively, we could assume that all federal citizens, or the representatives in the federal assembly, elect a federal policymaker. All subsequent results also apply to each of these alternative settings.
} 
and $t=0$, the implemented policy is ex-post efficient. Anticipating $x^{B}$, region $A$ then chooses it investments at stage 1 so as to maximize (C stands for Centralization)

$$
U_{C}^{A}(\cdot)=E_{\theta}\left\{\beta V\left(x^{B}, a, \theta\right)+t x^{B}-(1-\alpha) C\left(x^{B}, e, \theta\right)\right\}-\phi(a)-\psi(e) .
$$

Accordingly, the equilibrium investments $\left(a^{C}, e^{C}\right)$ are implicitly determined by the first-order conditions

$$
\begin{gathered}
E_{\theta} \beta V_{a}\left(x^{B}, a, \theta\right)+\left[V_{x}\left(x^{B}, a, \theta\right)-C_{x}\left(x^{B}, e, \theta\right)\right] \frac{d x^{B}}{d a}=\phi_{a}(a), \\
-E_{\theta}(1-\alpha) C_{e}\left(x^{B}, e, \theta\right)+\left[V_{x}\left(x^{B}, a, \theta\right)-C_{x}\left(x^{B}, e, \theta\right)\right] \frac{d x^{B}}{d e}=\psi_{e}(e) .
\end{gathered}
$$

Unlike the decentralization regime, an indirect effect appears in these optimality conditions. While again a larger investment of region $A$ boosts the project size, the project choice $x^{B}$ is now made by the other region, giving region $A$ an incentive to manipulate this choice. ${ }^{24}$ Notice that the indirect effect is positive - and thus enhances investment incentives - only if $V_{x}\left(x^{B}, \cdot\right)-C_{x}\left(x^{B}, \cdot>0 .{ }^{25}\right.$ Obviously, this condition is satisfied only if grants to region $A$ are sufficiently large so that $x^{B}<x^{*}$. Conversely, the indirect effect is negative if grants are small and $x^{B}$ exceeds $x^{*}$ (and thus exceeds the policy preferred by $A$ as well).

Given these considerations, regions at the constitutional stage now face the following tradeoff. Substantial grants which trigger a small policy level $x^{B}$ yield a small direct investment effect and a positive indirect effect, or vice versa. Whenever value-enhancing investments play a role, this tradeoff cannot generally be resolved in favor of large or small grants. In particular, the induced policy can either be larger or smaller than efficient, depending on the specific functional forms. We can state the following results.

Proposition 4. Consider centralization without ex-post bargaining. If the region undertakes only cost-reducing investments or if $\beta=1$, efficiency prevails with the same grant policy $\left(t^{*}=t^{P}, \alpha=0\right)$ that is optimal under decentralization. Otherwise,

\footnotetext{
${ }^{24}$ In long form, the indirect effect is $\left[\beta V_{x}\left(x^{B}, a, \theta\right)+t-(1-\alpha) C_{x}\left(x^{B}, e, \theta\right)\right] d x^{B} / d i$ for $i=e, a$. Since $x^{B}$ is given by (14), this can be simplified to the expressions stated in (16) and (17).

${ }^{25}$ Verify that that $x^{*}$ is always in between $x^{A}$ and $x^{B}$. Specifically, $x^{A}>x^{*}>x^{B}$ holds for large grants, while the reverse is true if grants are small.
} 
an efficient outcome is again infeasible, and the optimal project choice may be larger or smaller than $x^{*}(\cdot)$.

Proof: For $\alpha=0$ and the Pigouvian output grant $t=t^{P}$, project size is $x^{B}=x^{*}$ and condition (17) holds at $e=e^{*}(a)$. To establish the second result, observe that the indirect effect in (16) is non-zero only if $x^{B} \neq x^{*}$. Hence, $x^{B}=x^{*}$ is incompatible with $a=a^{*}(e)$ unless $\beta=1$. Moreover, in contrast to decentralization, the optimal $x^{B}$ can be smaller than $x^{*}$ : while raising $x^{B}$ above $x^{*}$ boosts the direct investment effect in (16), the now negative indirect effect may dominate.

In summary, neither democratic centralization nor decentralization generate an efficient outcome when value-enhancing investments are feasible. Both governance modes yield different economic outcomes when the second-best efficient grant schemes are in place. Performance would be identical for grant provisions yielding efficient policy outcomes $x^{A}=x^{B}=x^{*}$. However, we found that $x^{A}>x^{*}$ is optimal under decentralization while $x^{B}$ smaller than $x^{*}$ may be optimal in a centralized regime. ${ }^{26}$ For this reason, when inter-regional bargaining is disregarded and central decisionmaking is political rather than benevolent, a clearcut comparison of regimes is elusive. In the remainder, we ask whether stronger and more intuitive conclusions emerge in a scenario where politicians are allowed to negotiate final project sizes with each other, an issue addressed in the remainder of the paper.

\section{$6 \quad$ Federalism with Political Bargaining}

This Section incorporates another element of real-world politics into the model. ${ }^{27}$ Specifically, we will allow politicians from different regions to negotiate the final

\footnotetext{
${ }^{26}$ Decentralization unambiguously dominates centralization if the optimal $x^{B}$ is larger than $x^{*}$ (which means the indirect investment effect under centralization is negative). However, if the indirect effect is sufficiently sizable, it is optimal to have $x^{B}<x^{*}$, because the positive indirect effect causes more efficient investments. Clearly, these considerations render a welfare ranking of governance structures impossible.

${ }^{27}$ This is done in a way which borrows from Lülfesmann (2002) who, however, considers a more restricted model. His paper does not analyze the case of a benevolent central government, focuses on value-increasing investments, and disregards output grants.
} 
policy outcome after uncertainty on benefits and costs has been resolved. Because the policy project is associated with spillovers, there are benefits from such a policy coordination prior to the final decision on $x$. Taking recourse to Coase (1960), these renegotiations will induce an efficient outcome provided all parties have complete information when gathering at the bargaining table. This condition is satisfied in our framework and, therefore, rational politicians will in stage 2 enter negotiations and agree on the ex-post efficient policy $x^{*}(a, e, \theta)$. In contrast to the previous literature, we assume political negotiations to be feasible not only in the centralization regime, but under decentralization as well. ${ }^{28}$

For concreteness, we follow the property-rights literature (see, e.g., Hart, 1995) and assume that the unfolding bargaining process between the regional representatives results in the generalized Nash-bargaining solution. Thus, in equilibrium each region obtains its governance- and transfer-dependent disagreement payoff, plus a fixed share of the bargaining gain which becomes available when $x(\cdot)$ rather than the respective disagreement policy is implemented. The shares reflect a region's relative bargaining strength and are parameterized as $\gamma \in[0,1]$ for region $A$ and $(1-\gamma)$ for region $B$, respectively. ${ }^{29}$

In what follows, this setting is first explored for the regime of decentralized governance. Then, we investigate democratic centralization where decisions again require a majority of delegates in the federal assembly.

\subsection{Decentralized Politics with Bargaining}

Under decentralization, region $A$ can autonomously decide on its policy projects. Nevertheless, there are gains from trade ex post, which can be realized if the region

\footnotetext{
${ }^{28} \mathrm{As}$ explained in the Introduction, we disregard transaction costs that may render an efficient outcome infeasible. Imposing transaction costs would not alter our qualitative results unless they differ across regimes, which we do not see as plausible in many situations. After all, we do not see a compelling reason why the possibility to renegotiate should be linked to the choice of authority structures as fixed in the constitution.

${ }^{29}$ While one may argue that these bargaining weights are related to the size, political, or economic importance of regions, we remain agnostic with respect to the determinants of bargaining strength, and also abstract from the possibility of 'renegotiation design' that is sometimes discussed in the literature (see, e.g., Aghion et al., 1994).
} 
enters negotiations with the government in $B$ after investments have been expended and the state of the world has become clear. Suppose first that negotiations with region $B$ fail. Then, region $A$ will in stage 3 again implement a project of size

$$
x^{A}(a, e, t, \alpha, \theta)=\arg \max _{x} \beta V(x, \cdot)+t x-(1-\alpha) C(x, \cdot) .
$$

Accordingly, a switch from policy $x^{A}(\cdot)$ to policy $x^{*}(\cdot)$ increases total surplus by an amount $\Delta_{D P}=\left[V\left(x^{*}, \cdot\right)-C\left(x^{*}, \cdot\right)-\left(V\left(x^{A}, \cdot\right)-C\left(x^{A}, \cdot\right)\right)\right]=S^{*}(a, e, \theta)-$ $\left.S\left(x^{A}, a, e, \theta\right)\right) \geq 0$ which represents the bargaining surplus under decentralized politics $(D P)$. Frictionless negotiations will in equilibrium be successful and region $A$ appropriates a share $\gamma$ in Nash bargaining. In stage 1 , region $A$ therefore maximizes $U_{D P}^{A}(\cdot)=E_{\theta}\left[S^{A}\left(x^{A}, a, e, \theta, \alpha, t\right)+\gamma\left(S^{*}(a, e, \theta)-S\left(x^{A}, a, e, \theta\right)\right)\right]-\phi(a)-\psi(e)$.

Using the envelope theorem, the associated the first-order conditions for equilibrium investments $\left(a^{D P}, e^{D P}\right) \operatorname{are}^{30}$

$$
E_{\theta}\left[(\beta-\gamma) V_{a}\left(x^{A}, \cdot\right)+\gamma V_{a}\left(x^{*}, \cdot\right)-\gamma\left[V_{x}\left(x^{A}, \cdot\right)-C_{x}\left(x^{A}, \cdot\right)\right] \frac{d x^{A}(\cdot)}{d a}\right]=\phi_{a}(a)
$$

and

$$
E_{\theta}\left[-(1-\alpha-\gamma) C_{e}\left(x^{A}, \cdot\right)-\gamma C_{e}\left(x^{*}, \cdot\right)-\gamma\left[V_{x}\left(x^{A}, \cdot\right)-C_{x}\left(x^{A}, \cdot\right)\right] \frac{d x^{A}(\cdot)}{d e}\right]=\psi_{e}(e)
$$

for $(a, e)=\left(a^{D P}, e^{D P}\right)$, respectively. In contrast to our previous scenario in Section 4 where political bargaining was ruled out, the first order conditions now exhibit several novel effects. The direct effect changes because for given $x^{A}(\cdot)$, investments improve not only the region's default payoff but at the same time, they affect the available bargaining surplus. ${ }^{31}$. Second, investments now trigger an indirect effect (i.e., the last terms in (19) and (20)), which we might call the 'influence' effect of investing. This effect emerges because investments positively affect the choice of

\footnotetext{
${ }^{30}$ We require program (DP) (as well as program (CP), see below) to be well behaved. This is achieved if the investment cost functions $\phi(\cdot)$ and $\psi(\cdot)$ are sufficiently convex.

${ }^{31}$ Larger investments raise $x^{*}(\cdot)$, thus boosting $S\left(x^{*}(\cdot)\right.$ and the bargaining surplus from which region $A$ reaps a fraction $\gamma$. At the same time, though, investments raise both regions' default payoffs which has countervailing effect on the bargaining surplus. While the former effect dominates only if $x^{A}(\cdot)<x^{*}(\cdot)$, the total effect (taking the effect on default payoff into account) of a larger $x^{A}(\cdot)$ on the direct effect in (19) is strictly positive as long as $\beta>\gamma$.
} 
the default project size, and therefore, the region's share of the bargaining surplus $\Delta_{D P} .^{32}$ Specifically, if grants are large and the default policy $x^{A}$ is larger than efficient, we have $V_{x}\left(x^{A}\right)-C_{x}\left(x^{A}\right)<0$, making the influence effect positive and enhancing investments. Intuitively, since $x^{A}(\cdot)>x^{*}(\cdot)$, raising the default project further increases the bargaining surplus (by reducing total default payoffs), part of which is reaped by region $A$. By the same token, the indirect effect is negative for $x^{A}(\cdot)<x^{*}(\cdot)$, and it disappears altogether for $x^{A}(\cdot)=x^{*}(\cdot)$.

Suppose that regions agree on an optimal grant system in stage 0. Consider first the left-hand side of (19), region $A$ 's marginal return from value-increasing investments. For any cost grant $\alpha \geq 0$, there exists some output grant $t$ which raises $x^{A}(\cdot)$ above $x^{*}(\cdot)$ and renders the indirect effect positive. At least if $\beta>\gamma$ so that the spillover effect is not too pronounced and the direct effect is positive, it is then possible to implement $a^{*}(e)$ by appropriate choice of the constitutional grants which trigger the optimal default policy $x^{A}>x^{*}{ }^{33}$ For any $\alpha$, we can indicate the corresponding output grant which achieves this outcome as $\hat{t}(\alpha)$. Notice that any optimal grant design must in fact have the property that $x^{A}>x^{*}$ : for a default policy $x^{A}$ which is smaller than efficient, the indirect effect in (19) would be negative while the direct effect is not large enough to generate proper investment incentives.

Next, consider (20). Note first that for the same reason as in the scenario without bargaining, efficient cost-reducing investment can again be implemented without any Pigouvian cost grant $(\alpha=0)$. Fixing the output grant in a way that $x^{A}(\cdot)=x^{*}(\cdot)$, the indirect effect disappears and efficiency is attained. In contrast to the case analyzed in the previous section, though, the absence of a cost grant is now by no means necessary to induce an efficient outcome. To see this, note that for any choice of $\alpha \leq 1-\gamma$, the direct effect is positive. By adjusting the output grant, it is then possible to make the direct effect arbitrarily large, and the influence effect unambiguously positive. By continuity, there must exist some $\tilde{t}(\alpha)$ that allows to

\footnotetext{
${ }^{32} \mathrm{By}$ the envelope theorem, an increase in $x^{A}(\cdot)$ and $x^{*}(\cdot)$ has only a second-order effect on both region $A$ 's default payoff $S^{A}\left(x^{A}, \cdot\right)$ and on the efficient total surplus $S\left(x^{*}, \cdot\right)$ so that under decentralization, the corresponding derivatives are zero in (19) and (20). In contrast, changes in the default project size will affect region $A$ 's default payoff under centralization, and will have a crucial role in our analysis of the centralization regime below.

${ }^{33}$ We invoke part c) of Assumption 1 here.
} 
achieve $e^{*}(a)$.

We are now prepared to investigate whether efficient value-increasing and costreducing investments are feasible at the same time. Remember that at least if $\beta \geq \gamma$, efficient value-enhancing investments $a^{*}(e)$ are implementable through constitutional grants $(\alpha \geq 0, \hat{t}(\alpha))$. Similarly, any constitution with $(\alpha \leq 1-\gamma, \tilde{t}(\alpha))$ implements $e^{*}(a)$. Taken together, a first-best result prevails if the conditions $\beta \geq \gamma$ and $\hat{t}\left(\alpha^{*}\right)=\tilde{t}\left(\alpha^{*}\right)$ are satisfied for some $\alpha^{*}<1-\gamma$.

Analyzing these conditions yields the following results.

Proposition 5. Consider decentralized governance. In the political bargaining process, inter-regional renegotiations lead region A to implement the socially optimal policy level $x^{*}(a, e, \theta)$. Moreover,

(1) Suppose region A can undertake only one type of investment, e or a. For cost-reducing investments, various combinations of constitutional grant policies implement an efficient outcome. This positive outcome extends to valueenhancing investments (at least) if spillovers are not too pronounced, $\beta>\gamma$.

(2) Suppose region A can undertake both value-enhancing and cost-reducing investments. In this case, the first best generically prevails for any $\beta>\gamma$, and the optimal grant policy calls for positive output and cost subsidies.

Finally, under the optimal grant design $\left(\alpha^{*}, t^{*}\right)$, region $A$ 's default project size satisfies $x^{A}(\cdot)>x^{*}(\cdot)$.

Proof: see the Appendix.

These results say that when political bargaining is taken into account, decentralized authority yields efficiency in a wide range of economic situations. Accordingly, the outcome improves upon the decentralized no-negotiations setting when an optimal grant system is in place. ${ }^{34}$ Efficiency again prevails if the region can undertake only

\footnotetext{
${ }^{34}$ With no or an inefficient grant system in place, a commitment not to negotiate may be beneficial, even though it causes an inefficient project choice. For example, in a setting with ex post bargaining and $\alpha=t=0$ so that $x^{A}(\cdot)<x^{*}(\cdot)$, the negative influence effect reduces investment incentives. This effect can be so severe that it outweighs the inefficiencies arising in a system where bargaining is prohibited.
} 
cost-reducing investments. In sharp contrast to the earlier scenario without political bargaining, however, a first best outcome is also achieved in situations where the region undertakes value-enhancing investments, and generically so if the project region's own benefit from the public project are sufficiently large (i.e., $\beta>\gamma){ }^{35}$ And even better, the same desirable outcome can be achieved in the general setting with cost-reducing and benefit-enhancing investments. In all these situations, subsidiarity reaches the Pareto frontier, with the help of a grant system that uses cost and output grants to push $A$ 's preferred default project $x^{A}$ above $x^{*}{ }^{36}$

There is a powerful economic intuition behind these findings. In a scenario where political bargaining is not allowed for, grants not only have to provide investment incentives for region $A$, but also to ensure an optimal policy choice. As we have seen in the last Section, these goals are generally incompatible. Now, with political negotiations, an efficient policy choice is achieved irrespective of the grant design, and the exclusive purpose of grants is in enhancing investments. A proper grant design must take into account that negotiations add an indirect investment effect to the project region's payoff. This indirect effect arises because a change in the default policy size reduces (as long as $x^{A}<x^{*}$ ) or increases (for $x^{A}>x^{*}$ ) the bargaining surplus which is shared between both regions. The indirect effect is thus positive if $x^{A}$ exceeds $x^{*}$, that is, if the grant promise to region $A$ is sufficiently generous. Since at the same time the direct investment effect is increasing in $x^{A}$ without bounds if $\beta>\gamma$, i.e., larger grants unambiguously push investment incentives upward, thereby implementing the first best.

If spillovers are strong, i.e., $\beta \leq \gamma$, the direct effect is negative and even when $x^{A}(\cdot)>x^{*}(\cdot)$, the direct and the indirect effect in (19) have opposite signs. This renders a general efficiency result infeasible in cases where spillovers are very pronounced. In some situations, though, decentralization achieves the first best no matter what the degree of spillovers, i.e., for any arbitrary combination of $(\beta, \gamma)$.

\footnotetext{
${ }^{35}$ For example, suppose a region's bargaining strength is a function of its population size only. For regions of equal size so that $\gamma=1 / 2$, the first best is then attained when the project generates a larger benefit in $A$ than in $B$.

${ }^{36}$ Interestingly, one can show that if $V(x, a, \theta)=g(x, \theta)+f(a, \theta) x$ and $C(x, e, \theta)=h(x, \theta)-$ $k(e, \theta) x$ so that $S_{x a}(\cdot)$ and $S_{x e}(\cdot)$ are independent of $x$, the uniquely optimal grant combination for the general case is some $t^{*}>0$, in combination with the Pigouvian cost grant $\alpha^{*}=\alpha^{P}=1-\beta$.
} 
This is demonstrated in two examples below, which are fully analyzed in the Appendix.

Example 1: Let $V(\cdot)=a \ln (1+x)$ and $C(\cdot)=\max \{(z-e) x, 0\}, z>0$. For $(a, e)=\left(a^{*}, e^{*}\right)$, condition $(19)$ can be written as

$$
(\beta-\gamma) \ln \left(1+x^{A}(\cdot)\right)+\gamma\left[\frac{1+x^{A}(\cdot)}{1+x^{F B}}-1\right]=(1-\gamma) \ln \left(1+x^{F B}\right) .
$$

The left-hand side of this condition increases in $x^{A}$ without bounds. Since the value of the right-hand side is bounded from above, some constitutional grant policy $(\alpha, t)$ implements a default policy $x^{A}\left(>x^{*}\right)$ that satisfies (19) for all parameter combinations $(\beta, \gamma)$, implementing efficient value-increasing investments. (In the Appendix, we show that efficient cost-reducing investments can be achieved at the same time.)

Example 2: Let $V(\cdot)=a x+y \ln (1+x)$ and $C(\cdot)=x^{2} / 2-e x$, with $y \geq 0$. The first-order condition (19) reads for $(a, e)=\left(a^{*}, e^{*}\right)$ and inserting $\alpha=1-\beta$ as a necessary condition for efficient value-increasing and cost-reducing investments (see the proof of Proposition 6),

$$
(\beta-\gamma) x^{A}-\gamma\left[\left(x^{*}-x^{A}\right)-\left(\frac{y}{1+x^{*}}-\frac{y}{1+x^{A}}\right)\right] \frac{\left(1+x^{A}\right)^{2}}{y+\left(1+x^{A}\right)^{2}}=(1-\gamma) x^{*}
$$

In the Appendix, we show that for any $y$, the Left-hand side of this condition is increasing in $x^{A}$ without bounds, implying that a first best outcome prevails for any $(y, \beta, \gamma)$.

\subsection{Centralized Politics}

Under centralized governance, the policy outcome is determined in a federal parliament by majority rule. While a majority faction in the assembly is then legally entitled to implement its preferred policy in principle, renegotiations with the minority are welfare improving and will lead to an outcome which reflects the mutual interest of all regions. ${ }^{37}$ Suppose again that delegates from the composite region $B$ form the

\footnotetext{
${ }^{37}$ Under the unanimity rule, region $A$ will strictly underinvest in cost-reducing as well as in value-enhancing activities whenever $\gamma<1$, and the initial grant policy is irrelevant. To see this,
} 
majority, and that political bargaining is successful. In the out-of-equilibrium event that stage-2 renegotiations fail, region $B$ will in stage 3 implement

$$
x^{B}(a, e, \theta)=\arg \max _{x}(1-\beta) V(x, a, \theta)-t x-\alpha C(x, e, \theta) .
$$

Unlike decentralization, the default policy (here $x^{B}$ ) is now increasing in the size of the externality $\beta$, and decreasing in both the output grant parameter $t$ and the cost grant parameter $\alpha$. Anticipating this default policy, as well as the outcome of stage-2 negotiations, region $A$ maximizes in stage 1 ( $C P$ stands for centralized politics)

$U_{C P}^{A}(\cdot)=E_{\theta}\left[S^{A}\left(x^{B}, a, e, \theta, \alpha, t\right)+\gamma\left(S^{*}(a, e, \theta)-S\left(x^{B}, a, e, \theta\right)\right)\right]-\phi(a)-\psi(e)$

and, using the envelope theorem, the first-order conditions for equilibrium investments $\left(a^{C P}, e^{C P}\right) \operatorname{read}^{38}$

$$
E_{\theta}\left[(\beta-\gamma) V_{a}\left(x^{B}, \cdot\right)+\gamma V_{a}\left(x^{*}, \cdot\right)+(1-\gamma)\left[V_{x}\left(x^{B}, \cdot\right)-C_{x}\left(x^{B}, \cdot\right)\right] \frac{d x^{B}(\cdot)}{d a}\right]=\phi_{a}(a)
$$

and

$E_{\theta}\left[-(1-\alpha-\gamma) C_{e}\left(x^{B}, \cdot\right)-\gamma C_{e}\left(x^{*}, \cdot\right)+(1-\gamma)\left[V_{x}\left(x^{B}, \cdot\right)-C_{x}\left(x^{B}, \cdot\right)\right] \frac{d x^{B}(\cdot)}{d e}\right]=\psi_{e}(e)$

for $(a, e)=\left(a^{C P}, e^{C P}\right)$. A comparison with the corresponding conditions for the decentralization regime immediately yields a preliminary but interesting result:

Proposition 6. Consider a Pigouvian grant system $(\alpha, t)^{P}$ that implements $x^{A}(\cdot)=$ $x^{B}(\cdot)=x^{*}(\cdot)$. Under any such system, investment outcomes under centralization and decentralization coincide.

Pigouvian grants trigger an ex-post efficient outcome in each regime, which causes the indirect effects to vanish. At the same time, they make the default payoffs

notice that delegates from either region can veto the implementation of any new policy. Since one region will always have an interest to do so in anticipation of subsequent bargaining, the default allocation is $x=0$ where region $A$ receives no grant payments. Accordingly, both regions share the bargaining surplus $S\left(x^{*}, a, e, \theta\right)$ in negotiations from which $A$ reaps a fraction $\gamma$. The first-order conditions then read $\gamma E_{\theta} S_{a}\left(x^{*}, a, \theta\right)=\phi_{a}(a)$ and $\gamma E_{\theta} S_{e}\left(x^{*}, e, \theta\right)=\psi_{e}(e)$, respectively, so that underinvestment is unavoidable unless region $A$ has all the bargaining power, $\gamma=1$.

${ }^{38}$ Note that $S_{x}^{A}\left(x^{B}, \cdot\right)=S_{x}\left(x^{B}, \cdot\right)$ since $S_{x}^{B}\left(x^{B}, \cdot\right)=0$. 
under decentralization and centralization identical. Hence, investment incentives coincide. $^{39}$

To continue with the analysis of (22) and (23), note that in comparison to decentralized governance, the sign of the indirect effect is now reversed for a given default policy $x$. In sharp contrast to decentralization, region $A$ has an incentive to influence the default policy not only in order to affect the bargaining surplus (a motive present under decentralization as well), but also in order to raise its own default payoff $S^{A}\left(x^{B}, \cdot\right)$. To see this, note that region $B$ selects a large default policy $x^{B}$ if and only if $A$ 's eligible grants are small, whereas region $A$ 's interests are the exact opposite. Region $A$ will thus invest more in order to raise $x^{B}$ and to increase its default payoff if grants are sizable, and vice versa. This default payoff effect dominates the countervailing bargaining surplus effect, implying that - in contrast to decentralized governance - the overall indirect effect is negative whenever $x^{B}>x^{*}$. Analyzing (22) and (23), we obtain

Proposition 7. Consider centralized governance with majority rule, and suppose that delegates from region $B$ form the majority. Then,

(1) if region $A$ undertakes only cost-reducing investments, there always exists a transfer scheme $\left(\alpha^{*}=0, t^{*}>0\right)$ which achieves the first-best outcome.

(2) If region A undertakes value-increasing activities or both types of investments, a first-best outcome is not generally achieved even if $\beta>\gamma$.

Proof: The Appendix demonstrates inefficient outcomes for our previous Examples 1 and 2 .

In conjunction with our previous findings, these results are the central part of our analysis. They show that centralized authority may perform worse than decentralized governance even if monetary grant provisions can be optimally set in either regime. Authority rights to implement its preferred matter, and tilt the optimal

\footnotetext{
${ }^{39}$ This equivalence result highlights the difference to the setting analyzed in Besley and Ghatak (2001): even for identical default project sizes, investment incentives in their framework differ across regimes because the marginal investment return ceteris paribus depends on the governance structure by assumption.
} 
governance structure in favor of decentralization, even though explicit incentives can tackle the underlying moral hazard problem. ${ }^{40}$

In addition, our findings suggest an economically intuitive explanation for this surprising outcome. Remember that under decentralization, larger grant payments trigger a larger default project, which raises not only the direct effect of investing but at the same time, the indirect effect. ${ }^{41}$ In simple terms, region $A$ 's incentives to raise its effort in response to a larger (default) quantity are thus aligned with its incentives to raise the default quantity further.

In sharp contrast, under centralization, the direct effect and the indirect 'influence' effect cease to work in the same direction. The default policy $x^{B}$ as chosen by the composite region $B$ will exceed the efficient level $x^{*}$, thus generating a large direct effect, only if grants are small so that region $A$ bears much of the project's implementation costs. Under these circumstances, however, region $A$ improves its own default (and overall) payoff by prompting region $B$ to reduce $x^{B}$, and reducing its investment is an instrument to do so. ${ }^{42}$ This misalignment of investment forces in general makes an efficient outcome impossible even if spillovers are not very pronounced. In particular, reconsider the previous examples in which decentralization established efficiency. For Example 2 with $V(\cdot)=a x+y \ln (1+x)$, centralization renders efficient value-increasing investments infeasible if $y$ is either sufficiently low, or sufficiently large. In Example 1 where $V(\cdot)=a \ln (1+x)$, inefficiencies even prevail for all conceivable combinations $(\beta<1, \gamma)$.

\footnotetext{
${ }^{40}$ Besides, the finding contradicts the obvious intuition according to which the first best can be achieved if the number of instruments is as big as the number of goals. In the present context, this is (often) true for one governance structure, but not for the other.

${ }^{41}$ As discussed in the previous Section, this is true if $\beta>\gamma$, and for the relevant grant parameters inducing $x^{A}>x^{*}$.

${ }^{42}$ The marginal change of region $A$ 's default payoff caused by a change in $x^{B}$ is $\beta V_{x}-(1-\alpha) C_{x}$. Using the condition that determines $x_{B}$, this becomes $V_{x}-C_{x}$ which is negative iff $x^{B}>x^{*}$. Intuitively, at a project level preferred by region $B$, any marginal change in $x^{B}$ does not change $B$ 's payoff, so that the full welfare effect is reaped by region $A$. Remember that in contrast, the derivative of $A$ 's default payoff under decentralization is zero, as a consequence of the envelope theorem.
} 


\section{Conclusion}

This paper addresses the question whether the effectiveness of a federal system depends on its governance structure, even if an optimally designed grant system is in place. According to the key finding emerging from our analysis, centralized and decentralized federal systems do not exhibit the same incentives when a project region is responsible for stages in the production process of public projects. This finding is in tension with a central tenet of the standard literature on federalism, namely that an appropriately chosen (Pigouvian) grant would make the economic outcome in each regime indistinguishable. As we show, the scope of this argument does not extend to our framework which incorporates a moral hazard component of government activities. In this setting, the governance structure is shown to shape the attainable outcome even under an optimal grant design.

There are also more specific results which are borne out in our analysis. As long as the central government is benevolent, centralization is preferable to decentralization and a first best outcome can be implemented. To achieve this outcome, positive cost-matching grants as well as output grants are to be paid to the investing region. Moving away from this ideal setting, we then analyze a framework where centralized policies are chosen in a partisan political process in which regional representatives pursue their own interests. If political negotiations are disregarded, neither centralization nor decentralization then reach the efficiency frontier, irrespective of the grant system in place. Both governance regimes suffer from the fact that grants are supposed to simultaneously implement an ex-post efficient policy outcome, and to provide optimal efficient investment incentives. While we found that these tasks cannot be accomplished at the same time, no economically intuitive characterization of the second-best optimal governance can be provided.

This changes when the possibility of political negotiations between regional politicians is taken into account. Perhaps the most striking conclusion of our analysis is that constitutional grant policies are systematically less effective in a centralized system when political bargaining is admitted. Under decentralization, grants and investment incentives are aligned. Large grants to the investing region trigger higher 
investments because they foster the region's interest to invest into its default policy, and to raise this default policy at the same time. In our political economy interpretation of centralized governance, majority regions can force a minority region to carry out public policies at a scale preferred by the majority. When the constitution requires the minority to bear a disproportionate share of the associated costs, this region has an incentive to invest less in order to make a large project less attractive for the ruling majority. Alternatively, when the minority region is eligible for large grants under the constitution (implying the majority bears most of the project costs), the majority regions will implement only a small-scale project and investment incentives for the investing region are again relatively low. Unlike decentralized governance, grants are thus negatively correlated with default policy levels, and they can in general not be adjusted in a way as to generate efficient investment incentives. Our analysis identifies this misalignment feature as an inherent problem of centralized governance.

Since political negotiations are a tool to realize some mutual gain, we found it crucial to incorporate them into an analysis of federal structures. Communication among decisionmakers happens on a constant basis in real-world politics, and the outcome of political negotiations is often enforceable to a large degree. While our results suggest that the possibility to bargain improves the relative performance of decentralized over centralized governance, our simple model is only a first step and future research should investigate the robustness of this result in more general frameworks. 


\section{Appendix}

\section{Proof of Proposition 2}

To prove part (1), consider cost-reducing investments. By inspection of (17), $\alpha=$ 0 in combination with some non-negative $t$ so that $x^{A}(\cdot)=x^{*}(\cdot)$ implements an efficient outcome. To prove part (2), consider value-increasing investments. For $\beta=1$ and $\alpha=t=0$, we have $x^{A}(\cdot)=x^{*}(\cdot)$ and (16) as well as (17) coincide with the conditions for efficient investments, so that a first-best outcome is attained. Conversely, for $\beta<1$, region $A$ chooses $a<a^{*}(e)$ even if $(t, \alpha)$ are chosen such that $x^{A}(\cdot)=x^{*}(\cdot)$. Accordingly, efficient investments are incompatible with an ex-post efficient policy choice (allocative efficiency) if the region undertakes value-increasing investments. Next, observe that increasing $x^{A}(\cdot)$ marginally above $x^{*}(\cdot)$ has only a second-order effect on allocative efficiency and on $e$ while the associated increase in $a$ induces a positive first order effect. As a consequence, the second-best optimal policy must entail $x^{A}(\cdot)>x^{*}(\cdot)$. Finally, if the region expends both value-increasing and cost-reducing investments, it cannot be optimal to distort $e$ away from the level that is optimal conditional on $x^{A}(\cdot)$. Hence, the second-best constitutional policy is characterized by $\alpha^{*}=0, t^{*}>0$ and $x^{A}(\cdot)>x^{*}(\cdot)$.

\section{$\underline{\text { Proof of Proposition } 3}$}

To prove the second part, note that since $x^{A}=x^{*}$ for the proposed Pigouvian grant structure, the indirect effect in (6) disappears and the first-order conditions (11) and (6) coincide. We now prove the first part, and consider a situation without grants. Comparing (6) and (11) shows that for any given policy level $x<x^{*}$, investments under decentralization strictly exceed those under centralization for any $\beta<1$. At the same time, the policy level $x^{A}$ which prevails under decentralization is strictly smaller than efficient which yields a countervailing effect with respect to overall efficiency. To show that decentralization can yield a larger social surplus $W=V-C-\phi-\psi$, consider now the following example: Let $V=a x, C=x^{2} / 2$, and $\phi(a)=a^{3} / 3$. Then, $x^{*}(a)=a, a^{*}=1$, and $x^{A}=\beta a($ for $\alpha=t=0)$. 
Region $A$ 's equilibrium investments then are $a_{D}=\beta^{2}$ under decentralization, and they are $a_{C}=\max \{0,2 \beta-1\}$ under a benevolent central government [insert in (6) to obtain the first-order condition $\left.\beta a+[\beta a-a]=a^{2}\right]$. Accordingly, equilibrium policies are $x\left(a_{C}\right)=\max \{0,2 \beta-1\}$ under centralization, and $x\left(a_{D}\right)=\beta^{3}$ under decentralization. Inserting, total surplus in the centralization regime is $W_{C}=0$ for $\beta \leq 1 / 2$, which implies that $W_{C}<W_{D}$. For $\beta>1 / 2, a_{C} \leq a_{D}$ and $x\left(a_{C}\right) \leq x\left(a_{D}\right)$ with strict inequality for any $\beta<1$, so that again $W_{C}<W_{D} \forall \beta<1$.

\section{$\underline{\text { Proof of Proposition } 5}$}

To prove part (1), consider first a situation where region $A$ can undertake only cost-reducing investments. Define $\tilde{t}(\alpha)$ as an output grant that implements $e^{*}(a)$ for given $a$ and given $\alpha$. For $\alpha=0, e=e^{*}(a)$ requires the indirect effect to disappear, i.e., $x^{A}(\cdot)=x^{*}(\cdot)$. Since $x^{A}(\cdot)$ is monotonically increasing in $t$ without bounds and $x^{A}(\cdot)<x^{*}(\cdot)$ for $t=0$ and $\beta<1$, there exists some $\tilde{t}(0)>0$ which implements $e=e^{*}(a)$. For any $\alpha<1-\gamma$, the direct effect is positive. Moreover, the output grant $t$ makes it possible to let $x^{A}$ become arbitrarily large. Since the indirect effect is positive for any $x^{A}>x^{*}$ and the direct effect becomes arbitrarily large as $x^{A} \rightarrow \bar{x}$ (refer Assumption 1e), $\tilde{t}(\alpha)>0$ exists for any $\alpha<1-\gamma$. Continuity then ensures that $\tilde{t}(\alpha)$ also exists for any intermediate $\alpha \in[0,1-\gamma) .{ }^{43}$

Next, consider value-increasing investments. Consider an arbitrary $\beta \geq \gamma$ and let $\hat{t}(\alpha)$ be an output grant that implements $a=a^{*}(e)$ for given $e$ and given $\alpha{ }^{44}$ For any $\beta<1$, implementing $a^{*}(e)$ requires the indirect effect to be positive, which in turn demands that the optimal grant design must ensure $x^{A}>x^{*}$. Note that the indirect effect is positive for any $x^{A}>x^{*}$ and converges to zero as $x^{A} \rightarrow x^{*}$. Also, the direct effect becomes arbitrarily large as $x^{A} \rightarrow \bar{x}$ (by Assumption 1e). By continuity, these arguments imply that $\hat{t}(\alpha)$ exists for any $\alpha \in[0,1]$.

To prove part (2), verify that the first best can be implemented if and only if there

\footnotetext{
${ }^{43}$ The optimal output grant $\tilde{t}(\cdot)$ needs not to be monotonic in $\alpha$. Note also that for $\alpha \geq 1-\gamma$, $\tilde{t}(\alpha)$ does not necessarily exist: any output grant that raises $x^{A}(\cdot)$ and thus boosts the indirect effect increases the negative direct at the same time. See, however, our arguments below.

${ }^{44}$ For $\beta<\gamma$, the direct effect is negative and a raise in $x^{A}(\cdot)$ triggers countervailing incentives. Accordingly, the first best cannot generally be ensured.
} 
exists some $\alpha$ with the property $\tilde{t}(\alpha)=\hat{t}(\alpha)$. We show that this condition is indeed satisfied for some $\alpha$ if $\beta>\gamma$. To do so, we first establish that $\hat{t}(\alpha)>\tilde{t}(\alpha)>0$ for $\alpha=0$. Recall that (20) is satisfied for $\alpha=0$ if and only if $x^{A}(\cdot)=x^{F B}(\cdot)$, i.e., the indirect effect is zero. This requires some positive output grant $\tilde{t}(0)>0$ for $\beta<1$. Conversely, to satisfy (19) for $a=a^{*}(e)$ under a cost-grant policy $\alpha=0$, it is necessary to have a strictly positive indirect effect whenever $\beta<1$. Accordingly, some default policy $x^{A}(\cdot)>x^{*}(\cdot)$ must be implemented. Indicate this policy as $x_{A}^{A}$. Since $x^{A}(\cdot)$ is increasing in $t, \hat{t}(0)>\tilde{t}(0)$ is immediate. Next, note that $\hat{t}(\alpha)$ is strictly decreasing in $\alpha$ : since $x^{A}(\cdot, \alpha, t)$ is increasing in $t$ and in $\alpha, x^{A}=x_{A}^{A}$ requires $\hat{t}(\cdot)$ to be decreasing. Fix $x^{A}$ at the level $x_{A}^{A}$, and consider (20). As $\alpha$ increases, the first term in this condition (the direct effect) decreases. Specifically, it becomes negative and decreases without bounds for cost grants $\alpha>1-\gamma$. Fix $t$ at the level $\hat{t}(\alpha)$ which leaves the indirect effect constant. Then, the size of the LHS of (20) decreases in $\alpha$ without bounds. Accordingly, there must exist some $\alpha^{*}>0$ such that $\hat{t}\left(\alpha^{*}\right)=\tilde{t}\left(\alpha^{*}\right)$, and a first-best outcome $\left(a^{F B}, e^{F B}\right)$ is attained.

\section{$\underline{\text { Proof of Proposition } 6}$}

To prove that efficient cost-reducing investments $e^{*}$ can generically be implemented, notice that a constitutional design with $\alpha=1-\beta$ and $t=0$ implies $x^{B}=x^{*}$, and satisfies (23). Next, we show that $a^{*}$ cannot generally be implemented for $\beta \geq \gamma$. To see this, consider the class of functional forms $V(x, a, \theta)=g(x, \theta)+f(a, \theta) x$ and $C(x, e, \theta)=h(x, \theta)-k(e, \theta) x$. Define

$$
z(x, \cdot) \equiv-\frac{V_{x}(x, \cdot)-C_{x}(x, \cdot)}{(1-\beta) V_{x x}(x, \cdot)-\alpha C_{x x}(x, \cdot)} \frac{1-\beta}{\alpha},
$$

and recall that $\phi_{a}\left(a^{*}\right)=E_{\theta} V_{a}\left(x^{F B}, a^{*}, \theta\right)$ and $\psi_{e}\left(e^{*}\right)=-E_{\theta} C_{e}\left(x^{F B}, e^{*}, \theta\right)$. Using these properties, $(22)$ holds for $(a, e)=\left(a^{*}, e^{*}\right)$ iff

$$
\begin{aligned}
& f_{a}\left(a^{*}\right)\left[E_{\theta}\left[(1-\gamma) x^{F B}(\cdot)-(\beta-\gamma) x^{B}(\cdot)-(1-\gamma) z\left(x^{F B}, \cdot\right)\right]=0\right. \\
& k_{e}\left(e^{*}\right)\left[E_{\theta}\left[(1-\gamma) x^{F B}(\cdot)-(1-\alpha-\gamma) x^{B}(\cdot)-(1-\gamma) z\left(x^{F B}, \cdot\right)\right]=0\right.
\end{aligned}
$$

By inspection, $\left(a^{*}, e^{*}\right)$ can be implemented only if $\alpha=1-\beta$ (also note that for this cost grant, (24) and (25) are identical). For $t=0$ so that $x^{B}=x^{*}$, the lefthand side of both conditions is positive. Increasing $t$ above zero lowers $x^{B}$ below 
$x^{*}$ which causes two effects. First, the (positive) sum of the first two terms in (24) and (25) goes up as $x^{B}$ decreases. On the other hand, though, the third terms in these conditions becomes unambiguously negative. These countervailing effects (which are also present for $t<0$ ) show that efficient investments cannot generally be implemented. (Example 2 below is an example for the class of functional forms analyzed here).

\section{$\underline{\text { Example } 1}$}

Let $V(\cdot)=a \ln (1+x)$ and $C(\cdot)=\max \{x(z-e), 0\}$ where $z$ is some positive constant. Suppose all optimization programs are well behaved, which is always the case for sufficiently convex investment cost functions. Considering interior solutions, we then have $x^{*}=a /(z-e)-1, x^{A}=\beta a /[(1-\alpha)(z-e)-t]-1$, and $x^{B}=$ $(1-\beta) a /[\alpha(z-e)+t]-1$.

We first analyze decentralization. In this regime, the optimality condition (19) reads for $(a, e)=\left(a^{*}, e^{*}\right)$ and using $\phi_{a}(\cdot)=V_{a}\left(x^{*}, \cdot\right)$ and $\frac{d x^{A}}{d a}=\left(1+x^{A}\right) / a$,

$$
(\beta-\gamma) \ln \left(1+x^{A}\right)-\gamma\left[\frac{a^{*}}{1+x^{A}}-(z-e)\right] \frac{1+x^{A}}{a^{*}}=(1-\gamma) \ln \left(1+x^{*}\right) .
$$

Since that $z-e=a^{*} /\left(x^{*}+1\right)$, this condition can be rewritten as

$$
(\beta-\gamma) \ln \left(1+x^{A}\right)+\gamma\left[\frac{1+x^{A}}{1+x^{*}}-1\right]=(1-\gamma) \ln \left(1+x^{*}\right) \quad\left(D P^{*}\right)
$$

Observe that for any $x^{A} \leq x^{*},\left(D P^{*}\right)$ cannot hold because (for $\beta<1$ ) the left-hand side is smaller than the right-hand side. Consider first $\beta \geq \gamma$. Then, increasing $x^{A}$ above $x^{*}$ raises the left-hand side without bounds. Accordingly, there exists some $\hat{x}_{A}^{*}$ - and some grant policy $(\alpha, t)$ implementing $\hat{x}_{A}^{*}$ - that generates efficient value-increasing investments. Next, consider $\beta<\gamma$. Note that the derivative of the left-hand side with respect to $x^{A},(\beta-\gamma) /\left(1+x^{A}\right)+\gamma /\left(1+x^{*}\right)$, is positive and increasing without bounds for any $x^{A}>x^{*}$ and any $(\beta, \gamma)$. Accordingly, there again exists some default policy level $x_{A}^{*}>x^{*}$ and some constitutional grant policy which implements the optimum.

We now show that efficient cost-reducing investments are feasible at the same time. To see this, note first that condition $\left(D P^{*}\right)$ does not directly depend on $\alpha$ (but only 
indirectly via $\left.x^{A}\right)$. Now, using $\psi_{e}\left(e^{*}\right)=-C_{e}\left(x^{*}, \cdot\right)$, rewrite $(20)$ as

$$
(1-\alpha-\gamma) x^{A}-\gamma\left[V_{x}\left(x^{A}, \cdot\right)-C_{x}\left(x^{A}, \cdot\right)\right] \frac{d x^{A}}{d e}=(1-\gamma) x^{*}
$$

Fix $x^{A}\left(>x^{*}\right)$ at the level required to satisfy $\left(D P^{*}\right)$. Verify that the second term in the above condition is then positive, and overinvestments prevail for $\alpha=0$. Increasing $\alpha$ - while lowering $t$ in a way as to leave $x^{A}$ constant - decreases the LHS of the condition without bounds, which immediately yields the result.

Consider now the Centralization regime. Replicating our previous steps and noting that $d x^{B} / d a=\left(1+x^{B}\right) / a$, the condition for efficient value-increasing investments now reads

$$
(\beta-\gamma) \ln \left(1+x^{B}\right)+(1-\gamma)\left[1-\frac{1+x^{B}}{1+x^{*}}\right]=(1-\gamma) \ln \left(1+x^{*}\right)
$$

Consider first $\beta \geq \gamma$. Again, underinvestments prevail for $x^{B}=x^{*}$. Taking the derivative of the left-hand side with respect to $x^{B}$ shows that its maximizer is $\hat{x}^{B} \equiv$ $\left(1+x^{*}\right)(\beta-\gamma) /(1-\gamma)-1$ if $x^{*}+1 \geq(1-\gamma) /(\beta-\gamma)$ (i.e., at an interior solution), and $\hat{x}^{B}=0$ otherwise. If $\hat{x}^{B}=0$, the above condition becomes $1-1 /\left(1+x^{*}\right)=\ln \left(1+x^{*}\right)$. It is then immediate that the left-hand side is smaller than the right-hand side for any $x^{*}>0$, and underinvestments prevail. Next, let $\hat{x}^{B}$ be positive. After inserting and manipulating, the above condition becomes

$$
(\beta-\gamma) \ln \frac{\beta-\gamma}{1-\gamma}+(1-\beta)=(1-\beta) \ln \left(1+x^{*}\right)
$$

By construction, underinvestments prevail if the left-hand side (LHS) of this condition is smaller than its right-hand side (RHS). To show this, define a function $Z=L H S-R H S$ and take the derivative with respect to $\beta$. Doing so yields $d Z / d \beta=$ $\ln (\beta-\gamma) /(1-\gamma)+\ln \left(1+x^{*}\right)$. Recalling that we require $x^{*} \geq(1-\gamma) /(\beta-\gamma)-1$, this derivative is identical zero for $x^{*}=(1-\gamma) /(\beta-\gamma)-1$, and strictly positive for any larger $x^{*}$. As a consequence, the function $Z$ is maximized at $\beta=1$. But for this level of the externality parameter, $Z=0$ and, as a consequence, underinvestments cannot be avoided for any $\beta<1$ (Note that for $\beta=1, x^{B}=x^{*}$ achieves efficiency, but region $B$ 's incentive to choose a positive default payoff is then exclusively driven by negative transfers). Finally, for $\beta<\gamma$, the left-hand side of the above condition 
is again maximized at $x^{B}=0$, and by our previous arguments underinvestments prevail. Taken together, regardless of the size of $x^{*}$, there exists no constitutional grant policy (i.e., no $x^{B}$ ) which implements an efficient outcome, irrespective of the parameter combinations $(\beta<1, \gamma)$.

$\underline{\text { Example } 2}$

Let $V(\cdot)=a x+y \ln (1+x)$ and $C(\cdot)=x^{2} / 2-e x, 0$, where $y$ is a non-negative constant. Suppose again that the investment cost functions are sufficiently convex $\mathrm{t}$ make the program well behaved. For given investments, the optimal policy size is implicitly defined by the first-order condition $a+e+y /\left(1+x^{*}\right)-x^{*}=0$.

Consider decentralization first. In this regime, the optimality condition (19) reads for $(a, e)=\left(a^{*}, e^{*}\right)$ and using $\phi_{a}(\cdot)=V_{a}\left(x^{*}, \cdot\right)$,

$$
(\beta-\gamma) x^{A}(\cdot)-\gamma\left[V_{x}\left(x^{A}(\cdot)\right)-C_{x}\left(x^{A}(\cdot)\right] \frac{d x^{A}(\cdot)}{d a}=(1-\gamma) x^{*}(\cdot) .\right.
$$

Region $A^{\prime}$ 's default policy $x^{A}(\cdot)$ is defined by the solution to $\beta\left[a+y /\left(1+x^{A}\right)\right]-(1-$ $\alpha)\left[x^{A}-e\right]+t=0$. One thus obtains

$$
\frac{d x^{A}}{d a}=-\frac{\beta}{-\beta y /\left(1+x^{A}\right)^{2}-(1-\alpha)}=\frac{\left(1+x^{A}\right)^{2}}{y+\frac{1-\alpha}{\beta}\left(1+x^{A}\right)^{2}}>0
$$

Using $\alpha=1-\beta$ as a necessary condition for efficient value-increasing and costreducing investments for the present class of functional forms (see the proof of Proposition 6), the above optimality condition becomes,

$$
(\beta-\gamma) x^{A}-\gamma\left[\left(x^{*}-x^{A}\right)-\left(\frac{y}{1+x^{*}}-\frac{y}{1+x^{A}}\right)\right] \frac{\left(1+x^{A}\right)^{2}}{y+\left(1+x^{A}\right)^{2}}=(1-\gamma) x^{*} \quad\left(D P^{*}\right) .
$$

When $\beta<1$, underinvestments prevails for any $x^{A} \leq x^{*}$ (the left-hand side LHS of condition $\left(D P^{*}\right)$ is smaller than the finite value of the right-hand side). Also, for $\beta \geq \gamma$, the LHS is increasing in $x^{A}$ without bounds. Accordingly, by the intermediate value theorem, there must exist some constitutional policy $(\alpha=1-\beta, t>0)$ and some associated $x_{A}(\cdot)$ which implements $\left(e^{*}, a^{*}\right)$. To see that this first-best result extends to the case $\beta<\gamma$, take the derivative of the LHS,

$$
\frac{d L H S}{d x^{A}}=(\beta-\gamma)+\gamma \frac{d x^{A}}{d a}\left[1-\frac{y}{\left(1+x^{A}\right)^{2}}\right]-\gamma\left[V_{x}-C_{x}\right] \frac{d\left[d x^{A} / d a\right]}{d x^{A}} .
$$


Since $\frac{d\left[d x^{A} / d a\right]}{d x^{A}}>0$, the third term in this condition is increasing for any $x^{A}>$ $x^{*}$. Also, the expression in brackets in the second term converges to unity for $x^{A}$ sufficiently big, and so does $d x^{A} / d a$. For $x^{A}$ chosen sufficiently large, the second term thus converges to a size of $\gamma$, implying that $d L H S / d x^{A}>\beta \geq 0$. Hence, by appropriate choice of $(\alpha=1-\beta, t>0)$ the LHS increases without bounds, and efficient value-increasing investments prevail. Finally, notice that efficient costreducing investments are achieved at the same time because $\alpha=1-\beta$.

Next, we analyze the Centralization regime. The relevant optimality condition (22) reads

$$
(\beta-\gamma) x^{B}(\cdot)+(1-\gamma)\left[V_{x}\left(x^{B}(\cdot)\right)-C_{x}\left(x^{B}(\cdot)\right] \frac{d x^{B}(\cdot)}{d a}=(1-\gamma) x^{*}(\cdot)\right.
$$

Since region $B$ 's default policy $x^{B}(\cdot)$ is implicitly given by $(1-\beta)\left[a+y /\left(1+x^{B}\right)\right]-$ $\alpha\left[x^{B}-e\right]-t=0$, one obtains

$$
\frac{d x^{B}}{d a}=-\frac{1-\beta}{-(1-\beta) y /\left(1+x^{B}\right)^{2}-\alpha}=\frac{\left(1+x^{B}\right)^{2}}{y+\frac{\alpha}{1-\beta}\left(1+x^{B}\right)^{2}}>0 .
$$

Inserting into the optimality condition yields $\left(C P^{*}\right)$,

$$
(\beta-\gamma) x^{B}+(1-\gamma)\left[\left(x^{*}-x^{B}\right)-\left(\frac{y}{1+x^{*}}-\frac{y}{1+x^{B}}\right)\right] \frac{\left(1+x^{B}\right)^{2}}{y+\frac{\alpha}{1-\beta}\left(1+x^{B}\right)^{2}}=(1-\gamma) x^{*} \text {. }
$$

We analyze this condition in what follows.

1) Consider $y=0$ so that the value function is linear. Check that the value of the Left-hand side of $\left(C P^{*}\right)$ is maximized at $x^{B}=0$. Then, notice that the optimality condition holds for $\alpha=1-\beta$ and $x^{B}=0$ so that efficient value-increasing investments are feasible. In addition, by our previous results, efficient cost reducing investments are achieved.

2) Consider now $y>0$. First, let $\alpha=1-\beta$, the necessary condition for simultaneous investment efficiency. Notice that for this combination, $d x^{B} / d a<1$ for any $y, x^{B}$. We first show that underinvestment is unavoidable if $y$ is small. To see this, take the derivative of the Left-hand side with respect to $x^{B}$, which yields

$$
\frac{d L H S}{d x^{B}}=(\beta-\gamma)-(1-\gamma) \frac{d x^{B}}{d a}\left[1+\frac{y}{\left(1+x^{B}\right)^{2}}\right]+(1-\gamma)\left[V_{x}-C_{x}\right] \frac{d\left[d x^{B} / d a\right]}{d x^{B}}
$$


For for $y \rightarrow 0, d x^{B} / d a$ converges to one and accordingly, the second term converges to $-(1-\gamma)$. Also, since $\frac{d\left[d x^{B} / d a\right]}{d x^{B}}=2 y(1-\gamma)\left(V_{x}-C_{x}\right)$, the third term converges to zero as $y \rightarrow 0$. Taken together, LHS is maximized at $x^{B}=0$ if $y$ is sufficiently small. Substituting $x^{B}=0$ into $\left(C P^{*}\right)$, this condition turns into

$$
(1-\gamma)\left[x^{*}-\frac{y}{1+x^{*}}+y\right] \frac{1}{1+y}=(1-\gamma) x^{*} .
$$

Simple algebra shows that this condition cannot hold whenever $y>0$. This proves that efficient cost-reducing and value-increasing investments cannot simultaneously be achieved if $x^{B}=0$ is the maximizer of the LHS of $\left(C P^{*}\right)$, which occurs (at least) if $y>0$ is sufficiently small. (Remark: According to results in the next paragraph, simultaneous efficiency is also unattainable for $y$ being sufficiently large).

Finally, we show that allowing for $\alpha \neq 1-\beta$ (such that efficient cost and value investments are incompatible) is no remedy to generate value-increasing investments if if $y$ is sufficiently large, and if $\beta \leq \gamma$. To validate this claim, note that the LHS of $\left(C P^{*}\right)$ is maximized for $\alpha=0$ so that $d x^{B} / d a=\left(1+x^{B}\right)^{2} / y$. To show that it is impossible to satisfy $\left(C P^{*}\right)$, note that the second term of LHS converges to zero for any $x^{B}$ as $y$ becomes large. Since the first term in LHS is non-positive, the result follows. 


\section{References}

Aghion, P., Dewatripont, M. and P. Rey (1994), "Renegotiation Design with Unverifiable Information," Econometrica, 62: 257-282.

Aghion, P. and J. Tirole (1997), "Formal and Real Authority in Organizations," Journal of Political Economy, 105(1): 1-29.

Alesina, A., Angeloni, I. and F. Etro (2005), "International Unions", American Economic Review, 95(3), 602-615.

Alesina, A. and E. Spolaore (1997), "On the Number and Size of Nations", Quarterly Journal of Economics, 112(4): 1027-1056.

Besley, T. and S. Coate (1997), "An Economic Model of Representative Democracy," Quarterly Journal of Economics, 108(1), 85-114.

Besley, T. and S. Coate (2003), "Centralized vs. Decentralized Provision of Local Public Goods: A Political Economy Analysis," Journal of Public Economics, 87(12): 2611-2637.

Besley, T. and M. Ghatak (2001), "Government vs. Private Ownership of Public Goods," Quarterly Journal of Economics, 116(4), 1443-1472.

Bird, R.M. and M. Smart (2002), "Intergovernmental Fiscal Transfers: Some Lessons from International Experience," World Development, 30(6), 899-912.

Caillaud, B., Jullien, B. and P. Picard (1996), "Hierarchical Organizations and Incentives," European Economic Review, 40(3-5): 687-695.

Casella, A. (1992), "On Markets and Clubs: Economic and Political Integration of Regions with Unequal Productivity," American Economic Review, 82(3-5): 115-121.

Coase, R.H. (1960), "The Problem of Social Cost," Journal of Law and Economics, 3: $1-44$. 
Crémer, J. and T. Palfrey (1995), "In or Out? Centralization by Majority Vote," European Economic Review, 40: 43-60.

Crémer, J. and T.R. Palfrey (2000) , "Federal Mandates by Popular Demand," Journal of Political Economy, 108, 905-927.

Crémer, J. and T.R. Palfrey (2006) , "An Equilibrium Voting Model of Standards with Externalities," Journal of Public Economics, 90(10-11), 2091-2106.

Dixit, A. (1996), The Making of Economic Policy: A Transaction-Cost Politics Perspective, Cambridge, MA: MIT Press.*

Ellingsen, T. (1998), "Externalities vs. Internalities: A Model of Political Integration," Journal of Public Economics, 68: 251-268.

Fernandez, R. and R. Rogerson (2003) , "Equity and Efficiency: An Analysis of Education Finance Systems," Journal of Political Economy, 111, 858-897.

Grossman, G. and O. Hart (1986), "The Costs and Benefits of Ownership: A Theory of Vertical and Lateral Integration," Journal of Political Economy, 94: 691719.

Hafer, C. and D. Landa (2005), "Public Goods in Federal Systems", mimeo, NYU.

Harstad, B. (2006), "Harmonization and Side Payments in Political Cooperation", American Economic Review, forthcoming.

Hart, O. and J. Moore (1990), "Property Rights and the Nature of the Firm," Journal of Political Economy, 98(6): 1119-1158.

Hart, O. (1995), Firms, Contracts, and Financial Structure, Oxford: Oxford University Press.

Inman, R. and D. Rubinfeld (1997), "Rethinking Federalism", Journal of Economic Perspectives, 11(4): 43- 64. 
Lockwood, B. (2002), "Distributive Politics and the Costs of Centralisation," Review of Economic Studies, 69(2), 313-338.

Lülfesmann, C. (2002), "Central Governance or Subsidiarity? A Property-Rights Approach to Federalism," European Economic Review, 46, 1379-1397.

Musgrave, R. A. (1959), The Theory of Public Finance: a Study in Political Economy, New York: McGraw-Hill.

Oates, W.E. (1972), Fiscal Federalism, New York: Harcourt-Brace.

Oates, W.E. (1999), "An Essay on Fiscal Federalism," Journal of Economic Literature, 37(3): 1120-1149.

Oates, W.E. (2005), "Toward a Second-Generation Theory of Fiscal Federalism," International Tax and Public Finance, 12: 349-373.

Persson, S. and G. Tabellini (1992) , "The Politics of 1992: Fiscal Policy and European Integration", Review of Economic Studies, 59(4): 689-701.

Persson, S. and G. Tabellini (1996), "Federal Fiscal Constitutions: Risk Sharing and Redistribution," Journal of Political Economy, 104(5): 979-1009.

Rubinchik-Pessach, A. (2005), "Can Decentralization Be Beneficial?," Journal of Public Economics, 89(7), 1231-1250.

Seabright, S. (1996), "Accountability and Decentralization in Government: An Incomplete Contract Model," European Economic Review, 40(1): 61-91. 